Linköping Studies in Science and Technology

Licentiate Thesis No. 1769

\title{
Thin Film and Plasma \\ Characterization of \\ PVD Oxides
}

\section{Ludvig Landälv}


Thin Film Physics Division

Department of Physics, Chemistry, and Biology (IFM)

Linköping University, SE-581 83 Linköping, Sweden

(C) Ludvig Landälv, 2017

ISBN: 978-91-7685-597-3

ISSN: 280-7971

Printed by LiU-Tryck, Linköping, Sweden, 2017 
The state-of-the-art tools for machining metals are primarily based on a metal-ceramic composite (WC-Co) coated with different combinations of carbide, nitride and oxide coatings. Combinations of these coating materials are optimized to withstand specific wear conditions. Oxide coatings are especially desired because of their possible high hot hardness, chemical inertness with respect to the workpiece, and their low friction.

This thesis deals with process and coating characterization of new oxide coatings deposited by physical vapor deposition (PVD) techniques, focusing on the $\mathrm{Cr}-\mathrm{Zr}-\mathrm{O}$ and $\mathrm{Al}-\mathrm{Cr}-\mathrm{Si}-\mathrm{O}$ systems.

The thermal stability of $\alpha-\mathrm{Cr}_{0.28} \mathrm{Zr}_{0.10} \mathrm{O}_{0.61}$ deposited by reactive radio frequency (RF)-magnetron sputtering at $500{ }^{\circ} \mathrm{C}$ was investigated after annealing up to $870{ }^{\circ} \mathrm{C}$. The annealed samples showed transformation of $\alpha-(\mathrm{Cr}, \mathrm{Zr})_{2} \mathrm{O}_{3}$ and amorphous $\mathrm{ZrO}_{\mathrm{x}}$-rich areas into tetragonal $\mathrm{ZrO}_{2}$ and bcc Cr. The instability of the $\alpha-(\mathrm{Cr}, \mathrm{Zr})_{2} \mathrm{O}_{3}$ is surprising and possibly related to the annealing being done under vacuum, facilitating the loss of oxygen. The stabilization of the room temperature metastable tetragonal $\mathrm{ZrO}_{2}$ phase, due to surface energy effects, may prove to be useful for metal cutting applications. The observed phase segregation of $\alpha-(\mathrm{Cr}, \mathrm{Zr})_{2} \mathrm{O}_{3}$ and formation of tetragonal $\mathrm{ZrO}_{2}$ with corresponding increase in hardness for this pseudo-binary oxide system also opens up design routes for pseudo-binary oxides with tunable microstructural and mechanical properties.

The inherent difficulties of depositing insulating oxide films with PVD, demanding a closed circuit, makes the investigation of process stability an important part of this research. In this context, we investigated the influence of adding small amount of $\mathrm{Si}$ in Al-Cr cathode on plasma characteristics, process parameters, and coating properties. $\mathrm{Si}$ was chosen here due to a previous study showing improved erosion behavior of Al-Cr-Si over pure Al-Cr cathode without Si incorporation in the coating.

This work shows small improvements in cathode erosion and process stability (lower pressure and cathode voltage) when introducing 5 at $\% \mathrm{Si}$ in the $\mathrm{Al}_{70} \mathrm{Cr}_{30}$-cathode. This also led to fewer droplets at low cathode current and intermediate $\mathrm{O}_{2}$ flow. A larger positive effect on cathode erosion was observed with respect to cleaning the cathode from oxide contamination by increasing cathode current with $50 \%$. However, higher cathode current also resulted in increased amount of droplets in the coating which is undesirable. Through plasma analysis the presence of volatile $\mathrm{SiO}$ species could be confirmed but the loss of $\mathrm{Si}$ through volatile $\mathrm{SiO}$ species was negligible, since the coating composition matched the cathode composition. The positive effect of added Si on the process stability at the cathode surface should be weighed against Si incorporation in the coating. This incorporation may or may not be beneficial for the final application since literature states that $\mathrm{Si}$ promotes the metastable $\gamma$-phase over the thermodynamically stable $\alpha$-phase of pure $\mathrm{Al}_{2} \mathrm{O}_{3}$, contrary to the effect of $\mathrm{Cr}$, which stabilizes the $\alpha$ phase. 
This licentiate thesis is part of my PhD work in Materials Science, in particular Thin Film Physics, starting in March 2013 (with a break for 7 months parental leave during 2015). This work is a collaboration between the Thin Film Physics Division at Linköping University and AB Sandvik Coromant, made possible through a Swedish Research Council (VR) industrial PhD student grant (Grant no: 621-212-4368). Furthermore, I have collaborated with the Institute for Applied Materials (IAM) at Karlsruhe Institute of Technology (KIT), Germany. During the course of the research, I was enrolled in Agora Materiae, a multidisciplinary doctoral program at Linköping University supported by the Swedish Government Strategic Research Area on Materials Science. 


\section{LIST OF INCLUDED PAPERS}

\section{Paper I}

\section{Structural Evolution in Reactive RF Magnetron Sputtered $(\mathrm{Cr}, \mathrm{Zr})_{2} \mathrm{O}_{3}$ During}

Annealing

L. Landälv, J. Lu, S. Spitz, H. Leiste, S. Ulrich, M. P. Johansson-Jõesaar, M. Ahlgren, E. Göthelid, B. Alling, L. Hultman, M. Stüber, P. Eklund

Submitted for publication

\section{Author's contribution}

I planned and coordinated the work, was involved in the TEM characterization, performed most of the analysis, and wrote the paper.

\section{Paper II}

Effect of Si on DC arc plasma generation from Al-Cr and Al-Cr-Si cathodes used in oxygen

I. Zhirkov, L. Landälv, E. Göthelid, M. Ahlgren, P. Eklund, J. Rosen

Submitted for publication

\section{Author's contribution}

I initiated the research idea, was involved in the planning of the work and the analysis, commented on successive drafts, and largely wrote the introduction and conclusion of the paper. 
Emmanuelle Göthelid, Lars Hultman, Per Eklund, Björn Alling, Sergey Simak, Cecilia Århammar, Mats Ahlgren, and Marco Zwinkels, for arranging for, and writing the application to the Swedish Research Council for an industrial PhD-grant and considering me as the co-applicant, hence opening up this possibility for me.

Per Eklund and Emmanuelle Göthelid for being my main supervisors from the university and industry, respectively. Thanks Per for introducing me to the world of vacuum science and stressing the importance of not using sloppy wording: e.g. it is called x-ray diffractogram not $\mathrm{x}$-ray spectrum! Emmanuelle thanks for your passion for the research topic and good feedback on my work and thanks both of you for your encouraging words when I needed them the most. Altogether it has helped me to get this far.

Mats Ahlgren for being my supportive manager during my expedition in Linköping up until now, reminding me of the target for the mission and the importance of delivering results, keeping the industrial context to this research.

Björn Alling for being my co-supervisor and introducer to the powerful world of theoretical modeling of materials. Lars Hultman for being my co-supervisor, always coming with quick and spot on comments on my work, as well as for letting me borrow your office.

Jun Lu for TEM-work and good collaboration and help with interpreting results and introducing me to the art of TEM. Fredrik Eriksson for all the help with XRD-related questions. Thomas Lingefelt, Harri Savimäki and Rolf Rohback for the help with all practical questions and work related to lab-equipment. Ali Khatibi for the introduction to the AlCrO system, and Sit Kerdsongpanya for the introduction to sputtering. Thin Film Physics Division with Jens Birch in the lead, altogether being a great pool of knowledge and fun.

Per-Olof Holtz for leading the Graduate school Agora Materiae, allowing me to meet and learn from many new colleagues in adjacent research fields, as well as arranging for several interesting study visits, such as CERN and synchrotron in Hamburg.

Igor Zhirkov and Johanna Rosén for the good and fruitful collaboration in the area of cahodic arc plasma analysis.

Michael Stüber with colleagues at KIT in Germany for the collaboration leading to the increased understanding of the $\mathrm{CrZrO}$ phase transformation upon annealing.

Mats Johansson-Jõesaar and Sergey Simak for important input and questions during the project meetings. 
My other colleagues and friends at LiU, David Engberg, Lina Tengdelius, Linda Karlsson, Arnaud Le Febvrier and many more for pleasant lunches and fika-breaks as well as discussions and help with research questions.

My colleagues and friends at Sandvik Coromant for helping out when needed and for showing interest when I' $m$ around in the building.

My lovely wife Maria Landälv for kind words, patience and fun times, all together making this a good time. Our parents for all the support, facilitating raising children at the same time as doing a $\mathrm{PhD}$.

Jesus, my Lord and Savior, for helping me to put this work into the big perspective of life, and for giving me the fundamental interest in, and the curiosity for discovering and restructuring His creation, and for helping me along this race. 


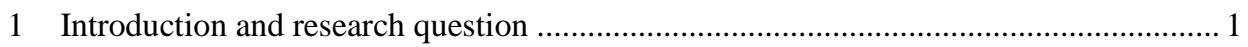

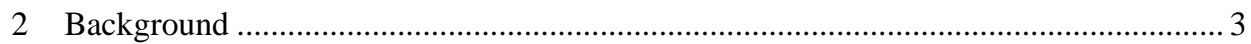

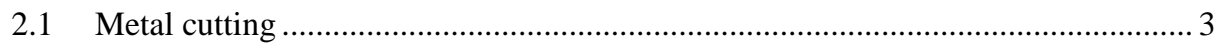

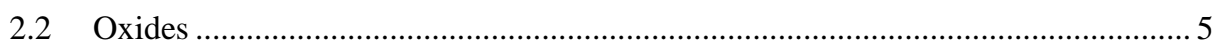

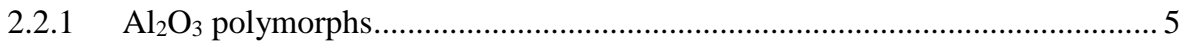

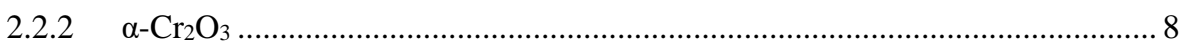

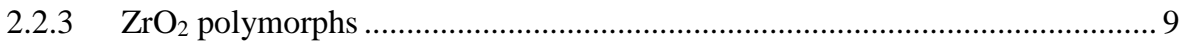

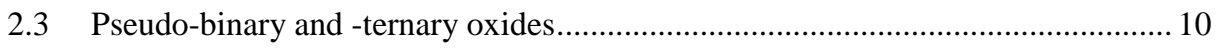

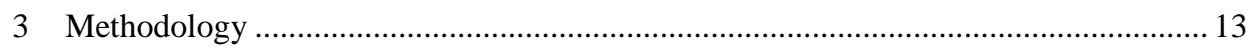

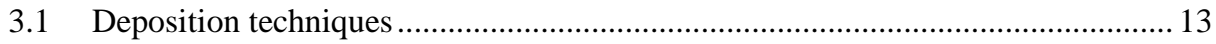

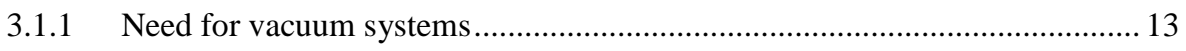

3.1.2 Unbalanced reactive RF-magnetron sputtering ......................................... 14

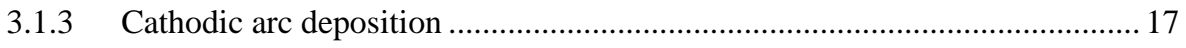

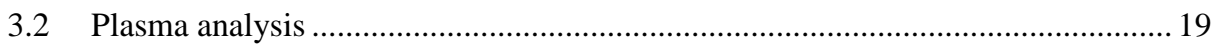

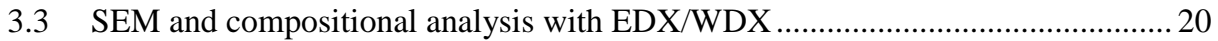

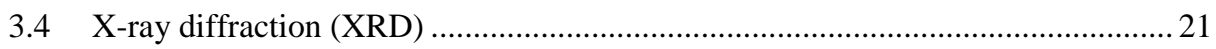

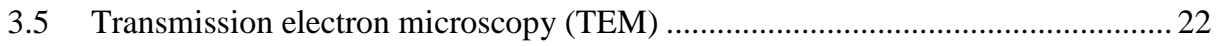

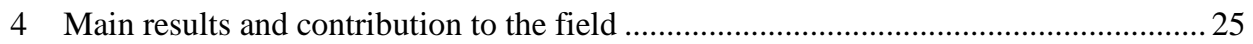

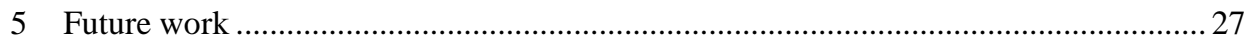

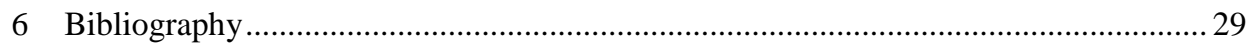

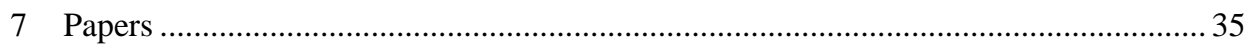





\section{Introduction and research question}

Being able to manufacture products from raw materials has been crucial to people throughout history. Depending on the type of material that should be shaped, tools and the materials they are made from have been adapted in order to reach the best possible performance with respect to manufacturing time and quality of the final product. With the start of the industrial revolution and the increased production and use of steel and other metal alloys, the machining of these materials became increasingly important. Machining operation, such as turning and milling, required tools which were more wear resistant than the workpiece material being shaped. Early turning and milling tools were made out of the same material as that to be machined, resulting in very poor tool life. Changing into tool steels, and later on high speed steel (ca 1900), gave a significant improvement in the metal removal rate. In the 1920's-30's, ceramic metal composite materials, such as hard metal cemented carbides (WC-grains in Co-metal matrix) were invented and started to be implemented into the metal cutting industry, resulting in a substantial enhancement in tool performance. This invention constituted a material with higher hot hardness than the workpiece material combined with sufficient toughness, resulting in a dramatic increase of the tool life and the possible cutting data (cutting speed, feed and depth of cut) used for machining. However, the complexity of integrating and using the new tool material in the manufacturing industry, due to the demand for more stable turning/milling machines, and the need of better grinding equipment (cutting edge regrinding), resulted in that the introduction of hard metal was slow until World War II and the years after the war [1].

The drawbacks of uncoated cemented carbide are their poor oxidation resistance and their reaction with the steel chip. This problem increased with the use of higher cutting speeds (resulting in higher tool temperature). In the late 60's, along with the introduction of indexable "throw-away inserts", coating of the tool with ceramic carbides TiC and later TiN and TiCN by chemical vapor deposition (CVD) was introduced. These coatings increased the surface hardness and chemical resistance without embritteling the entire tool, since the coatings were just some micrometers thick. After intense research, deposition of the first crystalline $\mathrm{Al}_{2} \mathrm{O}_{3}$ on the tool was achieved and introduced to the market 1975, followed by thicker oxide coatings in the 80 's $[1,2]$. This material has very low solubility in steel [3]. Combining the abrasive wear resistance of TiCN, with the high temperature chemical inertness of $\mathrm{Al}_{2} \mathrm{O}_{3}$, boosted the tool life and productivity. The main drawback of the CVD-coatings originated from the high deposition temperatures needed $\left(\sim 1000{ }^{\circ} \mathrm{C}\right.$ [4]), since these deposition techniques operate near thermodynamic equilibrium and requires high temperature to initiate chemical reactions. The high deposition temperature and the thermal expansion mismatch between the coatings and the substrate result in possible substrate-material-diffusion into the coating and a network of cooling cracks in the coating after cooling from the deposition temperature $[4,5]$. 
The introduction of physical vapor deposition (PVD) techniques, permitting deposition at lower temperatures and far from thermodynamic equilibrium, made new metastable coating compounds such as TiAlN ( $c a$ 1985) possible [6-8]. The lower deposition temperature enables the use of temperature-sensitive substrate such as high speed steel. The thermodynamically stable $\alpha-\mathrm{Al}_{2} \mathrm{O}_{3}$ oxide coatings, which boosted the CVD-coated products, however, proved to be difficult to obtain with these techniques. The reasons were twofold: insulating materials, such as oxides, are in opposition to the need for a closed electrical circuit in PVD deposition, and the lower deposition temperatures results in metastable phases rather than the thermodynamically stable phase.

Based on these conditions, this project aims to explore phase control in PVD oxide coatings. Specifically, I seek to achieve oxide coatings which have a desired crystal structure and are thermally and chemically stable with respect to the workpiece material at the temperature of use during metal cutting. The general approach is to either stabilize a metastable oxide compound at the temperature of use or to obtain, during the deposition, a thermodynamically stable compound which will remain stable at the temperature of use. The stabilization of the metastable phases or promotion of the thermodynamically stable phases during growth is realized through alloying. This is investigated in the $\mathrm{Cr}-\mathrm{Zr}-\mathrm{O}$ system and the Al-Cr-( $\mathrm{Si})-\mathrm{O}$ systems.

The Cr-Zr-O system was chosen because of being a combination of two engineering oxides having good mechanical and/or thermal properties showing solid solution in the corundum structure. The annealing study of $\mathrm{Cr}-$ rich $\alpha-(\mathrm{Cr}, \mathrm{Zr})_{2} \mathrm{O}_{3}$ coatings is aligned with the project goal of investigating the temperature stability of interesting compounds.

The Cr-Al-(Si)-O system was selected because the need of investigating the reported cathode erosion improvement by adding $\mathrm{Si}$ in the cathode without subsequent $\mathrm{Si}$ incorporation in the coating [9].The inherent difficulties with depositing insulating oxide films with PVD also make possible ways of improving the process stability an important part of this research, rendering plasma characterization important. Through plasma studies combined with coating characterization the effect on the three different material fluxes (ions, neutrals and droplets) present during cathodic arc deposition may be investigated and linked to the film growth. 


\section{Background}

\subsection{Metal cutting}

Metal cutting means removal of material, through chip formation, from a workpiece material in order to shape it into its desired form. This can be done through several different types of machining operations, which can be categorized in three main groups: turning, milling, and drilling. In Figure 1 (a), a turning operation is shown. The cylindrical workpiece material rotates around its center axis and the tool performs a facing operation towards the rotational center of the workpiece, marked with arrows. Figure 1 (b) shows a schematic figure of a plane perpendicular to the main cutting edge of the tool. The black arrows show the direction of movement of the different components. The geometry of the tool in combination with the cutting data and the intrinsic properties of the workpiece material (e.g. degree of work hardening) decide the shape of the chip and the cutting forces which in turn decide the generated maximum temperature during machining. The maximum temperature is obtained $\sim 300 \mu \mathrm{m}$ onto the rake face, see Figure 1 (b), depending on geometry, workpiece material, cutting data and coating material $[10,11]$. Most of the heat is generated where the chip starts to form in the primary sheer zone [12] and is then mostly transported away with the chip, hence flowing over the rake face and thus heating that area more than the flank face [10]. The heat load is significantly lower on the flank face than on the rake face due to less plastic deformation in the workpiece material in this contact area with the tool.

Flank wear is initiated just below the cutting edge due to the sliding contact between the newly cut workpiece and the tool. Nitride and carbide coatings are generally more resistant to flank wear than crater wear.

It is in the rake face region that $\alpha-\mathrm{Al}_{2} \mathrm{O}_{3}$ oxide coatings historically has proven to be the most efficient coatings for reducing crater wear originating from high temperature chemical and abrasive wear loads. $\alpha-\mathrm{Al}_{2} \mathrm{O}_{3}$ also works as a thermal barrier layer that sometimes permit the use of a tougher but thermally softer substrate. Reduced smearing of the workpiece material due to the low chemical interactions with it, and a low friction, is another positive effect of $\alpha$ $\mathrm{Al}_{2} \mathrm{O}_{3}[13]$. 

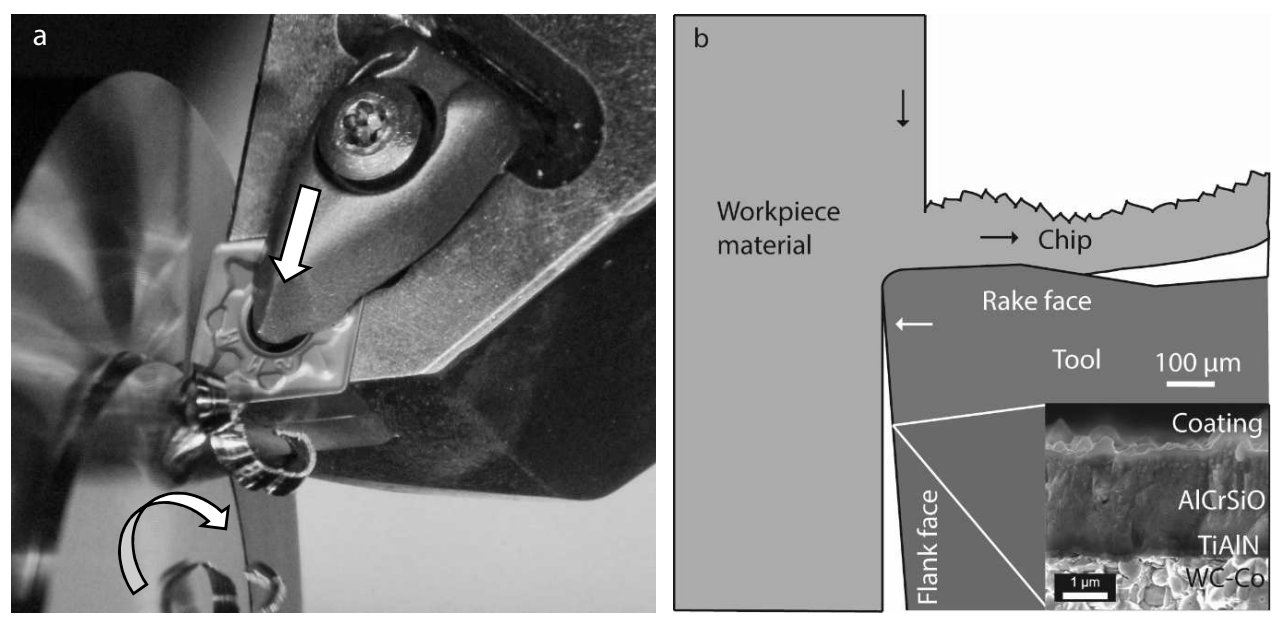

Figure 1. (a) Dry turning, a facing operation, in stainless steel (b) Schematic image of a cross section perpendicular to the cutting edge of a cutting tool during cutting. Arrows mark the direction of the moment of each part. The scale bar on the tool is to give a rough estimate of the scale of the tool compared to the coating thickness.

Milling is a machining operation where the cutter body rotates at high speed around its own axis. The rotating cutter body or the workpiece is then moved in contact with the other. Machining then typically starts with some degree of radial cutter engagement which is characteristic for a milling operation compared to a turning operation. In the later continues cutting tool engagement is common. In milling on the other hand maximum cutting tool engagement is half of the machining time, often much less, resulting in high mechanical and thermal load cycling. The typical milling wear, such as thermal cracks and chipping, originates from the thermal and mechanical cycling. In strongly intermittent turning, the wear often becomes similar to that normally observed for milling.

PVD coatings are predominantly used on milling inserts or turning inserts with high intermittent load, and/or finishing operations, leading to small depth of cut and low heat loads. The PVD coatings thus covers an application area where CVD-coated inserts often run into problem due to tensile stresses in the coating originating from their high temperature deposition. The high temperature deposition also leads to cooling cracks in CVD coatings which originates from thermal expansion mismatch between substrate and coating [11]. The need of very sharp cutting edges, matching small feed values, also promotes PVD coatings in milling and intermittent turning application because the PVD coatings generally are thinner coatings than CVD coatings. The possibility to tailor the residual stress levels in PVD coatings to a suitable compressive state, with different degrees of ion bombardment, is also beneficial for improving the resistance to cracks and brittle fractures. The comparable low deposition temperature with PVD is also beneficial for reducing cooling cracks during cooling after deposition. Altogether, these PVD coating specific application areas would benefit a lot from an expansion of the existing coating solutions with more PVD oxide coatings. This expansion would combine the inherently good properties from both PVD deposition techniques and oxide coating materials. Possible such oxide coating materials are explained in the next chapter. 


\subsection{Oxides}

\subsection{1 $\mathrm{Al}_{2} \mathrm{O}_{3}$ polymorphs}

In this chapter a background is given on the most extensively used oxide material for metal cutting, $\mathrm{Al}_{2} \mathrm{O}_{3}$. Being the starting point for this thesis and the aim of much research, an overview is presented on the most important crystal structures of the sesquioxide $\mathrm{Al}_{2} \mathrm{O}_{3}$ and some of the previous work done on $\mathrm{Al}_{2} \mathrm{O}_{3}$ coatings for metal cutting.

Aluminum oxide, $\mathrm{Al}_{2} \mathrm{O}_{3}$, exhibits many different metastable crystal structures and one thermodynamically stable structure, the corundum phase, denoted $\alpha$. The corundum structure is the most commonly sought phase of $\mathrm{Al}_{2} \mathrm{O}_{3}$ within the area of tool material (coating or bulk) for metal cutting. The structure is an $\mathrm{R} \overline{3} \mathrm{c}$ structure with $\mathrm{Al}$ in six fold coordinated $\mathrm{AlO}_{6}$ facesharing octahedrons. Figure 2 (a) show the rhombohedral unit cell of the $\alpha-\mathrm{Al}_{2} \mathrm{O}_{3}$ structure with the $\mathrm{Al}^{3+}$ coordinated in the oxygen octahedrons. Upon heating a single-crystal sample, the lattice expands more along the $c$-axis than the $a$-axis due to the repulsive $\mathrm{Al}$-Al forces. Thermal expansion data for the structure is given in ref [14]. Another way of describing the same structure is with closed packed arrays of $\mathrm{O}^{2-}$ ions stacked in an $\mathrm{ABABAB}$ order along the caxis. Between each layer $2 / 3$ of the octahedral holes are filled with $\mathrm{Al}^{3+}$. The $\alpha-\mathrm{Al}_{2} \mathrm{O}_{3}$ structure deviates from a perfectly closed packed structure in the way that the Al-Al distances are isotropic instead of being longer along the c-axis compared to the ones parallel to the basal plane. These small shifts are, however, normally omitted [15]. Figure 2 (b) shows the ordered metal vacancies on the metallic Al-sublattice which translates one octrahedral hole for each new metal sub-lattice layer. 
a

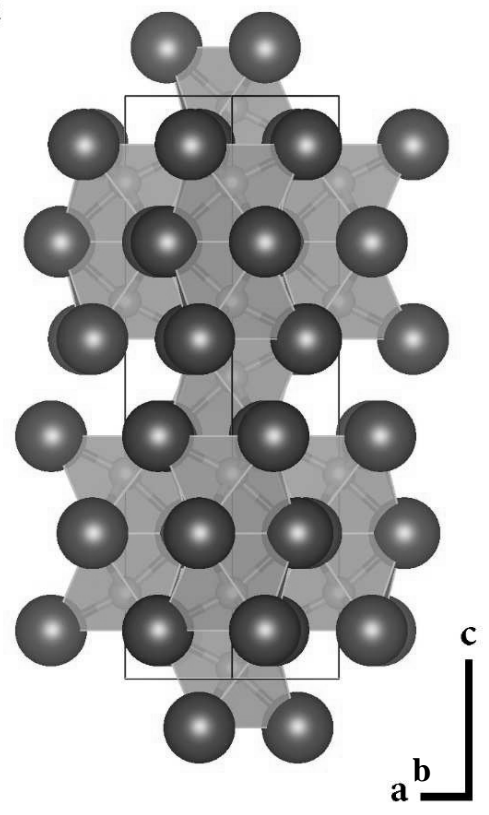

b

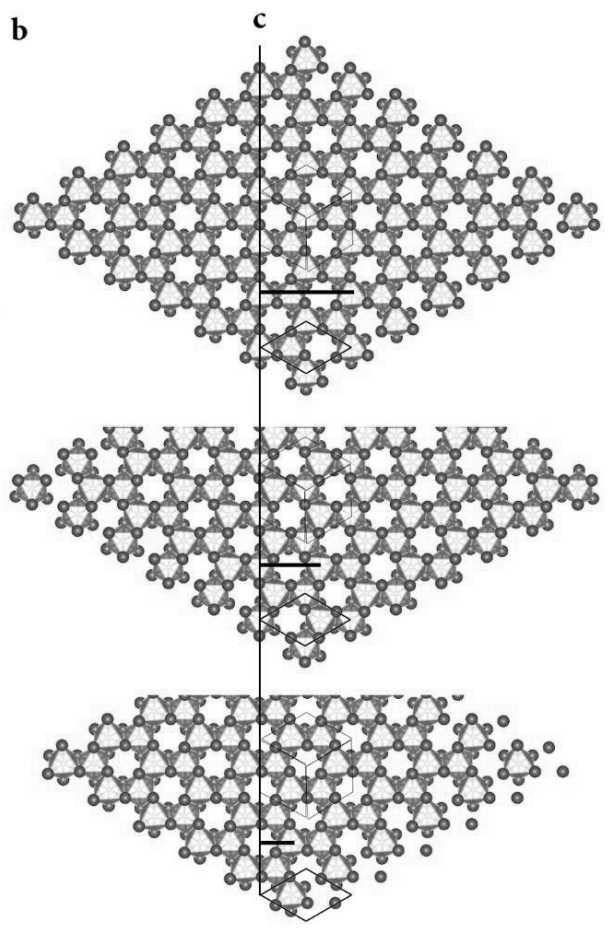

Figure 2. (a) Rhombohedral unit cell of the $\alpha-\mathrm{Al}_{2} \mathrm{O}_{3}$ phase oriented along the [110]-projection with c-axis vertical, showing the ABAB-stacking of oxygen atoms (big red spheres). Additional $O$ atoms has been added in order to complete all octahedral coordinated Al (small grey spheres) polygons $(b)$ show the ordered metal vacancies on the metallic Al-sublattice which translates one octrahedral hole for each new metal sub-lattice layer (shown with a black growing horizontal line)). Crystal structures made with VESTA.

Deposition of $\alpha-\mathrm{Al}_{2} \mathrm{O}_{3}$ with reactive pulsed magnetron sputtering on steel substrate was reported when increasing the substrate temperature over $700{ }^{\circ} \mathrm{C}[16,17]$. A detrimental effect of adding bias $(-50 \mathrm{~V})$ on the nucleation of $\alpha-\mathrm{Al}_{2} \mathrm{O}_{3}$ over $\gamma$-phase was reported by the same group [18]. This is somewhat contradictory to later work claiming that higher energy ion bombardment, single ionized $\mathrm{Al}+$ ions, is positive for the formation of $\alpha-\mathrm{Al}_{2} \mathrm{O}_{3}[19,20]$, by filtered cathodic arc deposition (FCA) up to $200 \mathrm{~V}$ bias [21]. Also using ionized metal species by means of HIPIMS can produce $\alpha-\mathrm{Al}_{2} \mathrm{O}_{3}$ with a wide range of bias voltage $[22,23]$. The discrepancy in the effect of biasing is possibly due to the different ions species that are accelerated by the bias. In the pulsed magnetron sputtering case, $\mathrm{Ar}^{+}$is accelerated but in the latter case it is metal ions or metal and Ar ions that are accelerated with the applied bias resulting in completely different ion bombardment of the substrate. Lower total pressure or higher $\mathrm{O}_{2}$ partial pressure also yield higher degree of energetic bombardment [24], which promoted $\alpha$ $\mathrm{Al}_{2} \mathrm{O}_{3}$ on a $\alpha-\mathrm{Cr}_{2} \mathrm{O}_{3}$ nucleation layer. There are several factors that have hindered further industrialization of the process: high deposition temperatures, difficulties with scaling power supplies (HIPIMS), and to create stable plasmas for threefold rotating substrates in a large scale deposition equipment. Thus, there are still no commercial cutting tools with PVD $\alpha-\mathrm{Al}_{2} \mathrm{O}_{3}$ even 20 years after the first claim of such a coating. 
The different metastable phases and their transformation routes has been reviewed by Levin and Brandon [25]. The metastable structures are divided into two main groups having a closed packed oxygen anion sublattice, either in face centered cubic ABCABC ( $\gamma$ cubic, $\eta$ cubic, $\theta$ monoclinic, $\delta$ either tetragonal or orthorhombic) or hexagonal close packed ordering ABAB $(\kappa$ orthorhombic, $\chi$ hexagonal). The different phases originate from the distinct ordering of the cations on the interstitial sites in between the two types of ordering of the oxygen sublattice. The same authors also discovered some additional monoclinic phases $\theta^{\prime}, \theta^{\prime}$, , and $\lambda$ with face center cubic anion ordering [26]. The phase transformations between the metastable phases are not reversible upon cooling and are therefore referred to as transition phases [27]. The metastable phases primarily used in metal cutting are kappa ( $\kappa)$ for CVD-deposited coatings [2] and gamma $(\gamma)$ for PVD-deposited coatings.

Early CVD $\alpha-\mathrm{Al}_{2} \mathrm{O}_{3}$ coatings has since the last $\sim 10$ years been shown to a large extent consist of transformed $\kappa$ (during deposition) instead of as grown $\alpha-\mathrm{Al}_{2} \mathrm{O}_{3}$. This phase transformation during growth results in a completely different defect filled microstructure than the now state of the art directly deposited $\alpha-\mathrm{Al}_{2} \mathrm{O}_{3}$. The high defect concentration in the $\alpha-\mathrm{Al}_{2} \mathrm{O}_{3}$ resulting from transformed $\kappa$-coatings are due to the $8 \%$ volume contraction during the $\kappa \rightarrow \alpha$ transformation [28]. This fairly recent discovery, considering the $\sim 40$ year's history of CVD $\mathrm{Al}_{2} \mathrm{O}_{3}$, show the complexity of obtaining good quality $\alpha-\mathrm{Al}_{2} \mathrm{O}_{3}$.

The $\gamma$ phase, space group $\mathrm{Fd} \overline{3} \mathrm{~m}$ spinel, is the most commonly obtained crystalline phase when depositing $\mathrm{Al}_{2} \mathrm{O}_{3}$ with PVD. Figure 3 shows an illustration of this structure with the unit cell marked with the black box. It is a cubic spinel-like compound with the cations distributed in three distinct interstitial positions (octahedral, tetrahedral and quasi-octahedral), thereby distinguishing it from the other cubic spinel transition phases through its cation ordering [27].

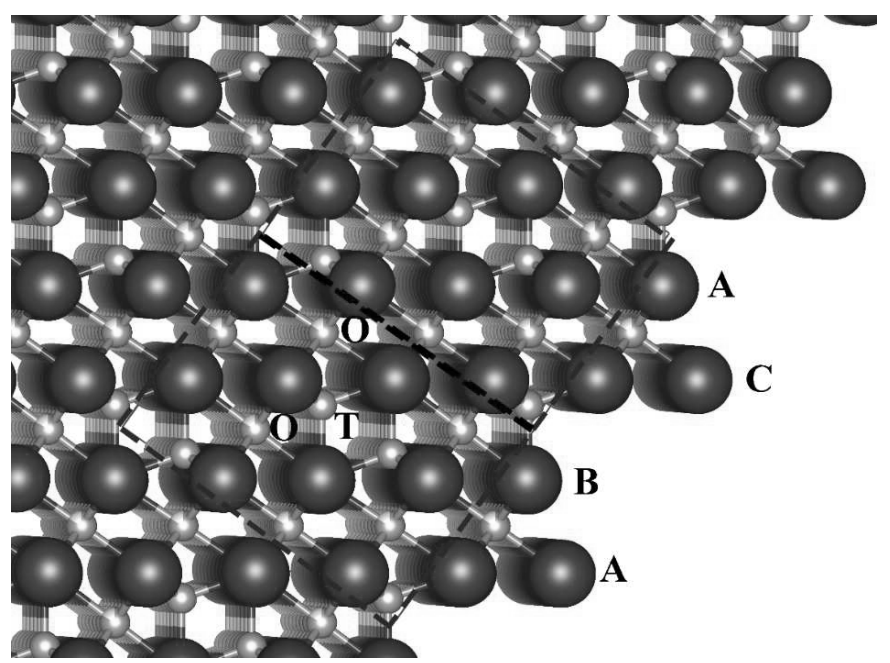

Figure 3. Shows the $\gamma-\mathrm{Al}_{2} \mathrm{O}_{3}$ structure along [110] zone axis (slightly off axis to show the depth perspective) with (021) normal pointing upward. Red big spheres are $O$ and small silver spheres are Al. ABC stacking is marked and $O$ for octahedral coordinated Al and T for tetrahedral coordinated Al. Black box is the unit cell but the cell is repeated 5 times in all direction to make the image. Crystal structure made with VESTA. 
In order to obtain $\gamma-\mathrm{Al}_{2} \mathrm{O}_{3}$ without amorphous phase, by means of reactively pulsed DC sputtering, a substrate temperature of at least $500{ }^{\circ} \mathrm{C}$ was needed as well as high power densities (with floating bias voltage) [29]. Similar deposition temperatures for reactive pulsed DC processes has been reported by several authors [16, 17, 30, 31]. With RF-sputtering it has been obtained at $450{ }^{\circ} \mathrm{C}-500{ }^{\circ} \mathrm{C}[32,33]$. Adding an RF-coil for further ionization of the material flux together with bias made deposition of $\gamma$-phase possible down to $\sim 300{ }^{\circ} \mathrm{C}$ [34]. The transformation from $\gamma$ to $\alpha$ upon annealing in air, under non-isothermal annealing, took place $\sim 1200{ }^{\circ} \mathrm{C}[29]$.

The effect on phase formation and relative phase stability by adding $\mathrm{Si}$ to the $\mathrm{Al}_{2} \mathrm{O}_{3}$ was recently investigated by Nahif et al. [35, 36]. Adding 2 at\% $\mathrm{Si}$ when depositing $\mathrm{Al}_{2} \mathrm{O}_{3}$ with filtered cathodic arc may increase the transformation temperature from $\gamma$ to $\alpha$ by $\sim 200{ }^{\circ} \mathrm{C}$, from $\sim 1050{ }^{\circ} \mathrm{C}$ to $\sim 1300{ }^{\circ} \mathrm{C}[36,37]$. Reactively pulsed DC sputtered amorphous $\mathrm{Al}_{2} \mathrm{O}_{3}$ coatings with up to 2.7 at $\% \mathrm{Si}$ showed an increased transformation temperature from amorphous to $\gamma$ with $\sim 110{ }^{\circ} \mathrm{C}$ and from $\gamma$ to $\alpha$ with more than $120{ }^{\circ} \mathrm{C}$ compared to pure $\mathrm{Al}_{2} \mathrm{O}_{3}$. The increased transformation temperatures were attributed to the increased $\mathrm{Si}-\mathrm{O}$ bond strength compared to Al-O [38]. The increased stabilization of the $\gamma$-phase may improve the performance and broaden the application area of the coating further than has been reported so far for pure $\gamma$-phase [3941]. The thermal load of a reported metal cutting test were not enough to cause transformation of the $\gamma$-phase [40].

The work to deposit corundum structured coating or stabilized metastable phases has continued from this background and has been focused more into alloying with different element in order to obtain stable phases at the temperature of use. This was the motivation for a plasma study of a pseudo ternary oxide $(\mathrm{Al}, \mathrm{Cr}, \mathrm{Si})_{2} \mathrm{O}_{3}$, Paper II.

\subsection{2 $\alpha-\mathrm{Cr}_{2} \mathrm{O}_{3}$}

Eskolaite, $\alpha-\mathrm{Cr}_{2} \mathrm{O}_{3}$, is isostructural with corundum, see Figure 2 (a), and is - in contrast to the $\mathrm{Al}_{2} \mathrm{O}_{3}$ system - the only crystalline form of $\mathrm{Cr}_{2} \mathrm{O}_{3}$. It has a slightly larger unit cell $(a$ and $b$

$4.959 \AA, c=13.594 \AA$ ) than $\alpha-\mathrm{Al}_{2} \mathrm{O}_{3}$ ( $a$ and $b 4.759 \AA, c=12.993 \AA$ ), due to the larger atom size of $\mathrm{Cr} . \alpha-\mathrm{Cr}_{2} \mathrm{O}_{3}$ being the only crystal structure at this oxygen content for $\mathrm{Cr}$ makes it easier to obtain this structure with PVD-techniques. It has been deposited at temperatures of $\sim 480{ }^{\circ} \mathrm{C}$ [42] with cathodic arc technique, and with different kind of sputtering techniques from $\sim 60^{\circ} \mathrm{C}$ [43] and $\sim 300^{\circ} \mathrm{C}$ (higher crystallinity) [44, 45]. This makes it suitable for stabilizing other compounds in the corundum structure. Stabilization can be done either by template growth (e.g., another material, such as $\mathrm{Al}_{2} \mathrm{O}_{3}$, is grown on $\alpha-\mathrm{Cr}_{2} \mathrm{O}_{3}$ and adopts that crystal structure) [46-48] or by alloying. When alloying other materials with $\mathrm{Cr}_{2} \mathrm{O}_{3}$ it promotes a solid solution in the corundum structure [33, 49-51]. 
$\alpha-\mathrm{Cr}_{2} \mathrm{O}_{3}$ is also one of the hardest naturally occurring oxide, with a hardness near $30 \mathrm{GPa}$. This hardness level is also seen for sputter-deposited phase-pure, dense stoichiometric $\alpha-\mathrm{Cr}_{2} \mathrm{O}_{3}$ [52], [48]. $\alpha-\mathrm{Cr}_{2} \mathrm{O}_{3}$ has not been used in its pure form as metal cutting tool material, but is extensively used for its good corrosion protection in, e.g., high alloyed steels.

On the other hand, $\mathrm{Cr}_{2} \mathrm{O}_{3}$ has been heavily used in alloy with $\mathrm{Al}$ and in this work also with $\mathrm{Al}$ and Si, see Paper II. The stabilizing effect of $\alpha-\mathrm{Cr}_{2} \mathrm{O}_{3}$ has also been investigated in the Crrich part of the $(\mathrm{Cr}, \mathrm{Zr})_{2} \mathrm{O}_{3}$ system in an annealing study, Paper $\mathbf{I}$.

It is worth noticing that, contrary to $\mathrm{Al}, \mathrm{Cr}$ can adopt three other valances states, 2+, 4+, and $6+$., which opens up for other types of oxides $\mathrm{CrO}, \mathrm{CrO}_{2}$, and $\mathrm{CrO}_{3}$. The latter is a highly toxic and carcinogenic compound due to the high oxidizing effect of $\mathrm{Cr}^{6+}$. The possible reaction of $\mathrm{Cr}_{2} \mathrm{O}_{3}$ to volatile $\mathrm{CrO}_{3}$ in an oxidizing environment [53] may be a reason that it has not been used in metal cutting in its pure form.

\subsection{3 $\mathrm{ZrO}_{2}$ polymorphs}

Pure $\mathrm{ZrO}_{2}$ exists in three different crystal structures: the standard temperature and pressure (STP) stable monoclinic phase $\mathrm{P} 2_{1} / \mathrm{c}$, and the metastable phases; tetragonal $\mathrm{P} 4_{2} / \mathrm{nm}$ c (from $\sim 1170{ }^{\circ} \mathrm{C}$ ) and cubic fluorite Fm $3 \bar{m}$ (from $\sim 2300{ }^{\circ} \mathrm{C}$ ), both at ambient pressures [54-57]. The crystallographic structure of the tetragonal phase is illustrated in Figure 4. See Paper I for the characterization of that phase in a pseudobinary oxide compound.

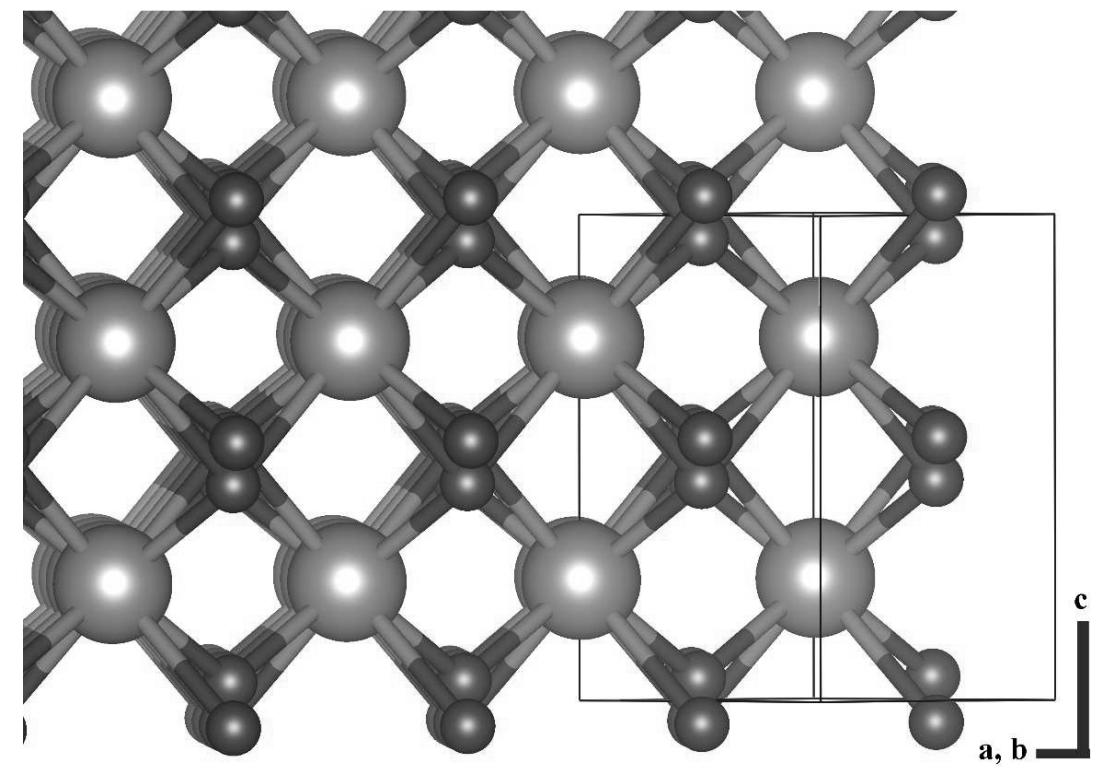

Figure 4. Crystallographic structure of the tetragonal $\mathrm{ZrO}_{2}$ phase along the [110]-projection (slightly off axis to show the depth perspective) with c-axis vertical showing the ABAB-stacking of oxygen layers (small red spheres) and Zr-layers (big purple spheres). The unit cell is marked with a black box. The image consist of 5 unit cells in each direction. Crystal structures made with VESTA. 
The tetragonal phase is the most commonly used phase and can be stabilized at STP by alloying with different early transition metal oxides, the most common being $\mathrm{Y}_{2} \mathrm{O}_{3}[58,59]$. The cubic fluoride phase is used as electrolyte in solid-oxide fuel cells due to its high ionic conductance $[60,61]$.

\subsection{Pseudo-binary and -ternary oxides}

Predicting what kind of crystal structure that will be obtained upon alloying is difficult for oxides, due to the ionic-covalent nature of the bonds. Several possible coordination and oxidation states of the transition metals, as well as a wide range of different plausible crystal structures also in the binary oxide system ads to the difficulties. Parameters to consider when entering the area of phase tailoring of $\mathrm{ABO}_{3}$ materials through alloying has been reviewed by Giaquinta and Loye [62]. The possibility to model the stability of new phases directly from first principles has become increasingly possible over the last decade due to the rapid growth in computational power. The development of the theoretical and numerical framework for electronic structure calculations based on density functional theory has also matured [63]. The studies of materials formed under non-equilibrium conditions such as PVD can, if care is taken, also benefit strongly from first-principles calculations as exemplified by the reviews of Abrikosov et al. [64] and Music et al. [65]. The pseudobinary and pseudoternary oxide coatings studied in this thesis, namely Cr-Zr-O (Paper I) and Al-Cr-Si-O (Paper II) systems, were however not chosen based on calculations, but on earlier experimental work [49] and $[9,66]$ respectively.

From a metal cutting tool material perspective, combining $\mathrm{Cr}_{2} \mathrm{O}_{3}$ with $\mathrm{ZrO}_{2}$ is interesting due to the low solubility of $\mathrm{ZrO}_{2}$ in iron [3] and $\mathrm{ZrO}_{2}$ low thermal conductivity [67]. The hardness and crystallographic stability could potentially be introduced by the naturally hard and stable $\alpha-\mathrm{Cr}_{2} \mathrm{O}_{3}$ [52]. The $\mathrm{Cr}-\mathrm{Zr}-\mathrm{O}$ was first deposited over the whole compositional range with reactive RF-magnetron sputtering by Spitz et al. [49]. They showed solid solution in the corundum structure at the $\mathrm{Cr}$-rich end of this pseude binary system. This was possible despite the facts that $\mathrm{Zr}$ has one higher valence than $\mathrm{Cr}$ and is significantly larger in size [68]. The high temperature binary phase diagram state higher solubility of $\mathrm{ZrO}_{2}$ in $\mathrm{Cr}_{2} \mathrm{O}_{3}$ than the other way around [69].

The thermal stability of $\mathrm{Cr}$-rich $(\mathrm{Cr}, \mathrm{Zr})_{2} \mathrm{O}_{3}$ coatings was investigated through annealing and post-annealing ex-situ characterization. After annealing up to $870{ }^{\circ} \mathrm{C}$, Paper I, the tetragonal $\mathrm{ZrO}_{2}$ phase was the only observed crystalline phase of $\mathrm{ZrO}_{2}$ at room temperature. This is possibly due to the small grain size in the coating $<30 \mathrm{~nm}$, as the tetragonal phase has a lower surface energy than the monoclinic one, and is thus stabilized even at room temperature [70, 71]. See Paper I for further details on the study. 
The pseudobinary phase diagram of $\mathrm{Al}_{2} \mathrm{O}_{3}-\mathrm{Cr}_{2} \mathrm{O}_{3}$ show full solid solution in the $\alpha$-structure over the entire compositional range at high temperatures, and a miscibility gap, shifted towards the $\mathrm{Al}_{2} \mathrm{O}_{3}$ rich side, at lower temperatures $[72,73]$. When depositing the material system by pulsed cathodic arc ( $\mathrm{Al}=0.70-0.25$ at $\%$ metal fraction), at temperatures $\sim 550{ }^{\circ} \mathrm{C}$, a corundum solid solution structure was obtained. Additional studies on the material system, using RFsputtering [74] and pulsed cathodic arc [66, 75] led to the discovery of a new, cubic, phase. The phase was concluded to be a defect-stabilized B1-like cubic phase with $33 \%$ vacancies on the metal sublattice [76]. A transition between the cubic B1-like structure to the thermodynamically stable corundum structure has been observed during growth [77] as well as upon annealing [66].

Arc deposition Al-Cr-O coatings as described above results in severe uneven cathode erosion, making its production on an industrial scale inefficient and costly owing to poor use of the cathode material. This is due to the extensive oxide island formation on the cathode surface, also referred to as cathode poisoning $[78,79]$. Adding 5 at $\% \mathrm{Si}$ to the cathode was reported to improve the cathode erosion and to reduce the oxide island formation. Surprisingly, the Si was not reported to have been incorporated in the coating. This was tentatively explained through formation of volatile $\mathrm{SiO}$ and changed melt composition of the cathode surface [9]. Reactive magnetron sputtering of $\mathrm{Al}_{0.52} \mathrm{Cr}_{0.4} \mathrm{Si}_{0.08}$ in almost pure $\mathrm{O}_{2}$ atmosphere resulted, however, in the B1-like cubic structure with similar Si-content in the coating as in the cathode [80]. This apparent discrepancy in Si uptake tendency for the oxide between the two PVD processes motivated my research in Paper II.

Thus in Paper II, a plasma study was performed on two cathode compositions, $\mathrm{Al}_{0.7} \mathrm{Cr}_{0.3}$ compared with $\mathrm{Al}_{0.7} \mathrm{Cr}_{0.25} \mathrm{SiO}_{0.05}$. The studies aim was to clarify the effect of $\mathrm{Si}$ on the coating composition including the presumable loss of $\mathrm{Si}$ through volatile $\mathrm{SiO}$. Due to the focus on the plasma characteristics in the study a mass-energy analyzer was mounted at the position where normally the substrate holder is situated. Previous studies showed that the heat generated from the arc source itself could be enough to damage the analyzer. Therefore, no external heating was used. Since no additional heating was used, the coatings were thus expected to be amorphous (and were not characterized with XRD). The presence of volatile $\mathrm{SiO}$ could be confirmed, but significant loss of Si cold not. The Si-content in the coating was measured to be in parity with the cathode composition, see Paper II for further details. 


\section{Methodology}

\subsection{Deposition techniques}

Applying of a coating has been part of mankind's history for thousands of years, where the goal has been to improve the appearance or usefulness of an item [81]. Nowadays, applying a coating of some thickness, ranging from atomic monolayer to several hundreds of $\mu \mathrm{m}$ is part of the surface engineering field, an increasingly important field of research and engineering over the last couple of decades [82]. There is a vast number of different ways of producing a coating onto a bulk material of some kind. Among these can be mentioned: thermal spraying (e.g. thermal barrier coatings for turbine blades, $\sim 500 \mu \mathrm{m}$ thick [67] ), electro plating $\sim 10 \mu \mathrm{m}$ (e.g. platinum bond coating [67]), Chemical vapor deposition (CVD) [82], Physical vapor deposition (PVD) [82], and many more. The common feature of PVD techniques is the vaporization of a solid through physical ejection of atoms or molecules into a low pressure vapor or plasma. The vapor or plasma consist of neutral or ionic species, which in turn condensates onto a substrate. Adding a reactive gas, e.g. $\mathrm{N}_{2}$ or $\mathrm{O}_{2}$, allows the formation of nitride or oxide compounds, respectively. PVD techniques encompass a vast array of different ways of vaporizing the source material: thermal evaporation, electron beam evaporation, different kinds of sputtering, filtered and unfiltered cathodic arc deposition, and pulsed laser deposition, each one having its advantages and drawbacks [82]. In this thesis, two types of PVD techniques have been used, reactive radio-frequency $(\mathrm{RF})$ magnetron sputtering and reactive direct current $(\mathrm{DC})$ cathodic arc evaporation, which is further described below.

\subsubsection{Need for vacuum systems}

PVD techniques require controlled atmosphere and pressure. Therefore, vacuum systems are used with varying degree of ultimate pressures. The vacuum system used in this work are either high vacuum (HV) system $\left(\sim 7 \cdot 10^{-4} \mathrm{~Pa}\right.$ ultimate pressure), which only need Viton o-rings as sealing materials, or ultra-high vacuum (UHV) system $\left(\sim 7 \cdot 10^{-6} \mathrm{~Pa}\right.$ ultimate pressure), which needs copper gaskets.

The level of ultimate pressure needed (also called base pressure) is determined by the demands of cleanness from gas impurities in the final deposition product. The most difficult impurities to reduce in a vacuum system is water vapor (easy condensing and available abundant in air) and hydrogen (permeating most materials, and difficult to pump) [83]. To reduce the water vapor content and obtain UHV condition in reasonable time, the vacuum system walls need to be baked, i.e., heated to $\sim 150{ }^{\circ} \mathrm{C}$ for several hours in order for the vapor to desorb. The cleanness demands are generally much higher for electrical and optical coating application compared to industrial wear resistant coating applications. For the wear resistant coating industry, a plasma etch prior to coating deposition cleans the surfaces that should be 
deposited. That in combination with high depositions rates (compared to impurity depositions rates) makes it possible to use HV systems with a base pressure of $\sim 6 \cdot 10^{-4} \mathrm{~Pa}$, as shown in the appended papers (not baked UHV system).

When lowering the pressure to these levels the motion of the gas particles changes from being collective/fluid to become individual and ballistic. This change in behavior is characterized by the gas particle mean free path, the distance between gas-gas collisions. At UHV pressure this is typically of the order of a meter, or at deposition pressure ( 0.4 Pa) $5-10$ $\mathrm{cm}$, similar to or slightly smaller than the typical deposition distance $\sim 10-20 \mathrm{~cm}$. The degree of gas-gas collisions is a very important feature in PVD-techniques since it is one of the parameters influencing the species energy arriving at the substrate.

\subsubsection{Unbalanced reactive RF-magnetron sputtering}

The process of sputtering consists of bombarding a material, named target or cathode, with accelerated inert gas ions, most commonly $\mathrm{Ar}^{+}$. The inert gas ions are generated in what is called a plasma, a quasi-neutral electron gas. Plasma is commonly referred to as the fourth state of matter and is an ionized gas which is electrically neutral when averaged over the entire plasma. In order for the sputter process to work the gas ions needs to be accelerated by a negative potential at the cathode to a high enough kinetic energy $(\sim 25 \mathrm{eV})$ in order to eject (sputter) new atoms from the cathode upon impact. This causes a collision cascade within the atomic surface layers of the cathode material upon impact.

If a constant negative voltage is applied (typically of the order of a few $100 \mathrm{~V}$ ) to the cathode, the technique is called DC-sputtering. This gives the highest deposition rates compared to different sputtering techniques since the sputtering process is on $100 \%$ of the time. This technique works well for depositing conducting materials. If the material is isolating to some degree a pulsing of the voltage with some degree of reversed polarity is needed in order to discharge the extra charge built up on the deposited isolated areas, both on the cathode and on the anode (substrate). In this work, Paper I, RF (radio-frequency: reserved $13.56 \mathrm{MHz}$ ) power supplies have been used. This type of pulsed power supplies use a sinusoidal voltage pulse ( $\sim 50 \%$ on time compared to DC-sputtering) with the RF-frequency to clear the cathode surface from charge built up. RF-pulsing was originally used for sputtering of completely insulating ceramic targets [84] but can also be used for sputter from metallic target in reactive gas such as $\mathrm{O}_{2} / \mathrm{Ar}$ mixture and it then help discharge the insulating layer formed on the cathode, which is the case in this work, Paper I.

The sputtering process is today almost always enhanced by a set of permanent magnets behind the cathode material. The sputtering process is then called a magnetron sputtering process. The permanent magnets cause a magnetic field $\mathbf{B}$ close to perpendicular to the accelerating electric field $\mathbf{E}$ in front of the cathode. This field traps a larger fraction of the 
electrons resulting from the sputter process. These electron will remain in front of the cathode surface bouncing alternating back and forth between the two poles of the magnets at the same time as they drift along the $\boldsymbol{E} \times \boldsymbol{B}$ path. The increased electron density in front of the cathode will increase the degree of ionization of the Ar gas and hence increase the plasma density. This leads to that a higher sputtering rate is obtained even though a lower pressure of Ar can be used in the deposition chamber.

If the magnetic strength of the center magnet is equivalent to the sum of the magnets at the periphery of the cathode, the magnetron is called balanced. In order to enhance the plasma density further away from the cathode (closer to the substrate) as well as increasing the deposition rate, an unbalanced magnetron is often used. This means that the center magnet has a lower strength than the surrounding magnets, opening up the magnetic confinement in front of the cathode, lowering the degree of ionization of the gas, but extending it further out in the deposition chamber. Using an unbalanced magnetron increases the gas ion and electron bombardment of the substrate and may lead to structural defects in sensitive coatings (e.g. aimed for electronic applications). This is not the case for metal machining coating and therefore unbalanced magnetrons have been used in the present work (Paper I).

The substrate, which is the object to be coated with the vaporized sputtered species, could either be at grounded, floating or biased electrical potential. This will greatly influence the properties of the resulting coatings since the arriving ion bombardment will transfer different amount of energy to the ad-atom on the growing coating surface depending on the acceleration voltage applied to the substrate. The change in energy on the incoming species will affect the surface mobility and hence the crystal structure as well as the microstructure and density of the coating to be grown. Grounded substrate will lead to a small bias corresponding to the potential difference between ground and the slightly positive plasma $\sim 5 \mathrm{~V}$. Floating potential means that the substrate is electrically separated from the ground and will adapt to the plasma potential, resulting in a slightly negative self-biasing of the substrate due to the electron bombardment, $-5 \mathrm{~V}$. Having a biased substrate means that the substrate is connected to an external voltage source where it is possible to set a sought substrate potential in order to obtain a specific energy level of ion bombardment. Having set a negative bias voltage will result in an electrical current proportional to the impinging Ar+ ion current. A typical voltage profile for sputtering can be seen in Figure 5, showing the cathode fall (target), the plasma potential $\mathrm{V}_{\mathrm{p}}$, the anode (being the grounded chamber wall in many lab-systems) and the floating $\mathrm{V}_{\mathrm{f}}$ or biased substrate (middle). 


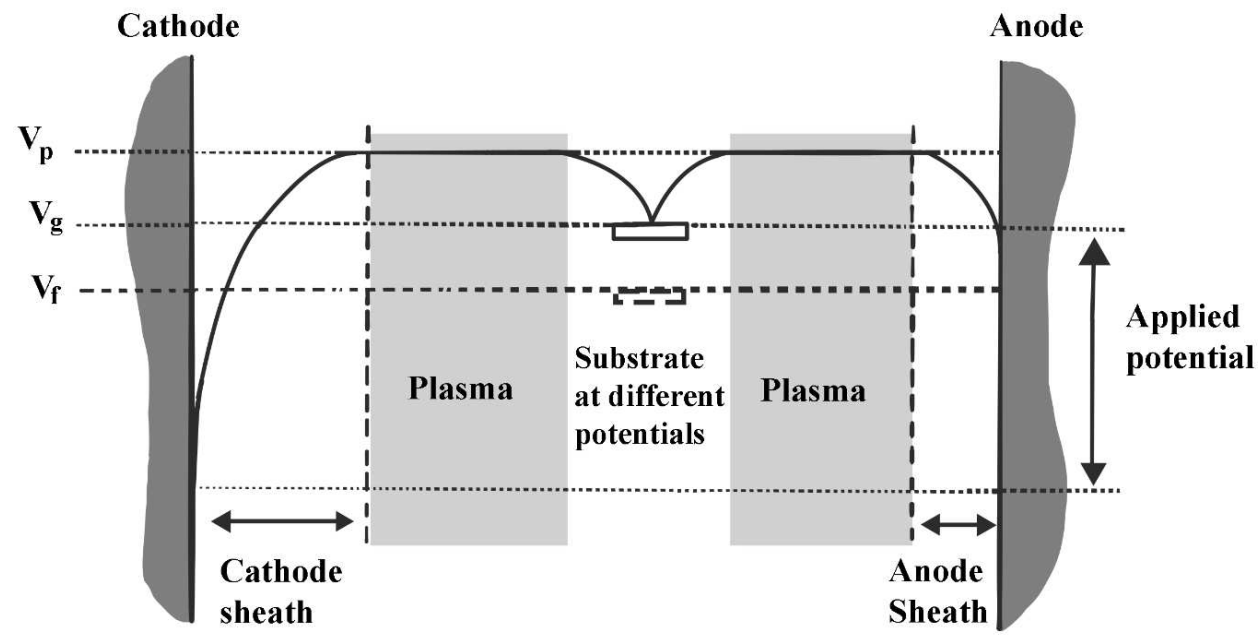

Figure 5. Schematic illustration of the voltage variation over cathode-plasma-anode setup in magnetron sputtering setup with large anode (chamber wall). Vp plasma potential, Vffloating potential for an inserted metal piece, e.g. substrate, Vg ground potential. Rework from [82].

A drawback of both DC and RF magnetron sputtering is that the cathode material is not ionized to any significant extant. The only significantly ionized species are the Ar+ which will not be incorporated into the coating, unless the bias is high. In that case some Ar+ could become implanted and trapped in the growing film. The residual Ar in the coating is an unwanted defect and inhibit the use of high bias in order to achieve for example densification of the film. Over the last $\sim 15$ years increasingly more work has been put into realizing depositing techniques permitting sputtering with a large fraction of metal ions, commonly grouped under the name High Power Impulse Magnetron Sputtering (HIPIMS) techniques [85, 86]. These techniques permits among other things to deposit denser films without incorporating $\mathrm{Ar}$ at otherwise similar conditions as for DC-sputtering. Another way of reaching high degree of ionization of the cathode material is the cathodic arc deposition technique, commonly used in industry since many years, and described in the next chapter. 


\subsubsection{Cathodic arc deposition}

Cathodic arc deposition take place in a different I-V regime compared to sputtering. Cathodic arc deposition is characterized by a small cathode fall voltage, generally referred to as burning voltage, of approximately $20 \mathrm{~V}$ [87] and a large currents 10 - hundreds of A. This is contrary to sputtering, having large voltage drop (hundreds of $\mathrm{V})$ and small currents $\left(\mathrm{mA} / \mathrm{cm}^{2}\right.$ range). The different I-V areas for the two techniques can be seen in Figure 6, sputtering between point $\mathrm{G}$ and $\mathrm{H}$ and cathodic arc deposition typically around point $\mathrm{J}$.

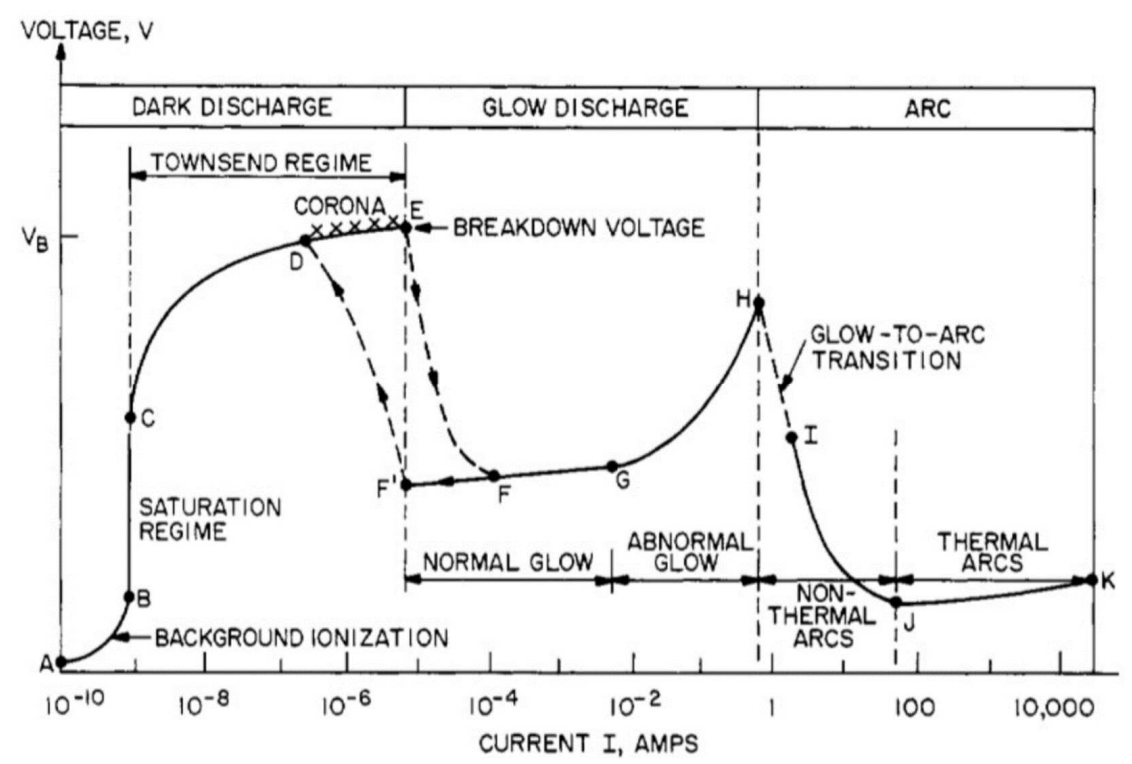

Figure 6. The universal Voltage-current characteristics of the DC electric discharge tube, used with permission from [88]

The difference in I-V regime is due to a completely different deposition mechanism in cathodic arc deposition compared to sputter deposition. The cathodic arc deposition proceeds through consecutive microexplosions on the cathode surface. One way of starting the process is by setting a current in the power supply followed by that a pneumatically driven trigger rod touches the cathode surface, initiating the first arc through a voltage breakdown. When the initial arc has formed new emission centers are continually formed, in a highly dynamic way, where the conditions are the most optimal on the cathode surface, as described below. An individual arc spot event is on the time scale of tens of nanoseconds. There are several models for describing the detailed arc event, giving different weight to different stages of the arc event, but the general notion is that each arc spot, arc explosion, or emission center, can be divided into four stages: 1 . the pre-explosion stage, 2 . the explosive emission stage, 3 . the immediate post-explosion stage and 4 . the final cooldown stage. In the first stage the conditions for creating an arc need to be met: physical protrusions generating high local electrical field due to rapid change in electric potential. This high electric field create high degree of electron emission and 
generates local heat and a more intense plasma. The work function of the cathode material also influence the ease which an arc is ignited. Adding an insulating surface oxide compound change the work function and electron emission, hence the arc spot initiation. When all the conditions are met in a specific spot electron emission with thermal runaway brings the spot into stage two. Stage two is characterized of explosive electron emission. This lead to a micro explosion of the heated cathode volume, transforming the solid material directly to plasma with high degree of cathode material ions, leaving a crater on its surface. In the third stage, the postexplosion stage, the molten cathode material in the crater emit electrons and evaporates cathode material neutrals which are ionized in close proximity to the cathode surface. In the fourth stage the intense emission is over and the area is cooling down, some metal vapor may still be emitted depending on material vapor pressure. The next arc has already ignited possibly on the prostrations from the previous arc, and in this way the process continues. The arc events have been showed to have fractal character: same appearance on a wide range of length scales. This gives a measure of the stochastic nature of the arc process. The violent arc events explains the high degree of ionization observed (almost $100 \%$ of the material flux) in an arc process as well as it gives an explanation to the cathode material droplets that one observe in the coating [87].

As mentioned above the arc formation depends on the formation of insulating compound on the cathode. The arc spot formed under insulating surface conditions may dissociate into several arc that will run in parallel, sharing the total current drawn through the cathode. This is called type 1 arc. Increasing the arc current to burn away the insulating compound may revert the arc mode to metallic, type 2 mode, for a given oxygen flow. A too much increased DC-arc current may lead to melting of the cathode material outside of the arc spot. Hence, this approach may not be possible to use as the only way for facilitating industrial application of reactive arc deposition of insolating compounds. Another way of obtaining the controlled erosion of the cathode in reactive atmosphere, without the risk of melting the cathode due to too high current, is pulsed DC-arc. With this technique the average power is held within the limits of what the cathode material can sustain without melting. On the same time the high current pulses clear the cathode from insulating compounds [50]. In this work, Paper II, a DC cathodic arc system was used for studying the fundamentals of arc plasma generation from $\mathrm{Al}_{0.7} \mathrm{Cr}_{0.3}$ and $\mathrm{Al}_{0.7} \mathrm{Cr}_{0.25} \mathrm{Si}_{0.05}$ cathodes used in $\mathrm{O}_{2}$ atmosphere. DC arc was used in order to study the most fundamental phenomena's of these material systems.

In order to reduce problem of metallic droplet, but benefit of the ionized metallic flux, different kinds of filters, magnetic and mechanic, have been used to reduce the particle flux but transmit the ionized metallic flux to the substrate. The drawback with this technique is the reduced deposition rate in combination with the extra equipment needed for the filters which has limited the industrial use of such techniques to coatings for optical, microelectronics and optoelectronical applications. This technique is well described in a review article on how to deposit metal oxides with this approach [89]. 


\subsection{Plasma analysis}

The plasma analysis, Paper II, was performed with a mass-energy-analyzer (MEA, Hiden Analytics model EQO). This analyzer combines an electrostatic energy analyzer and a quadrupole mass spectrometer permitting acquisition of charge-state-resolved ion energy distribution (IED) functions. The first step in the plasma analysis is to perform mass-scans at fixed ion energy in order to determine which mass-to-charge ratio should be chosen for each element and respective charge state, according to [90]. Isotope distribution of the elements, most important for $\mathrm{Cr}$, has been corrected for in line with [90]. Then the energy-scans at fixed mass-to-charge ratio was performed.

These distributions are important tools to understand the plasma composition since the asymmetric nature of the ion energy distribution, having a high energy tail, makes the plasma characterization underdetermined if just considering the most likely values, the peak values [91]. The main outcome from a plasma analyze as performed in Paper II are: 1) To "see" what kind of species, ions and neutrals, that are present in the deposition flux. 2) To determine the energy distribution of the ion species, especially if a high energy tail is present. The latter will be highly influenced by an applied bias.

Due to the complexity and adapting nature of the plasma potential which among other things depends on the anode potential, it is difficult to compare studies in detail between different systems if the plasma potential is not known. The acceleration of the ions in the sheath in front of the analyzer can then not be accounted for [92]. In the present study, Paper II, the chamber wall was the anode which was grounded. The plasma analyzer was also kept at grounded potential. No independent plasma potential measurement was done. However the plasma potential was calculated from the difference in anode sheath acceleration observed for the different ionic charge state according to method described in ref [93]. This calculation determined the plasma potential to be in the range of 3-5 V. For the high pressure (30 and 40 sccm) at low arc current (60 A) situation in Paper II, not showing several charge states, these calculations of the plasma potential were not possible and therefore they were not corrected for in the same way as for the lower flows. The focus for this study was however the general trends of ion energy distribution and to find out what kind of species that was present in the plasma. 
The used DC-arc setup had no permanent magnet behind the cathode. There are studies indicating that the addition of the magnet, primarily steering the arc and creating a more even cathode erosion, also can lead to increased ion energies, according to the findings by Anders and Oks [92]. The lack of a magnet in the present study may contribute to lower ion energies compared to what was generated but not measured in the original study of the effect of $\mathrm{Si}$ in Al-Cr cathode using pulsed steered arc [9]. However the effect of adding a pulsed bias, also used in the previous study, is the parameter having the highest effect on increasing the ion energies, affecting the final film properties, hence translating the non-biased IED to higher energies.

\subsection{SEM and compositional analysis with EDX/WDX}

Scanning electron microscope (SEM) is a versatile characterization tool with little need for sample preparation except for cleaning prior to analysis. The sample is put in a high vacuum chamber. The accelerated e-beam is scanned over the sample surface and interact with the surface of the sample. The interaction volume depends on the electron energy $(\sim 1-20 \mathrm{kV})$ and the analyzed material. The resulting scattered electrons may be analyzed with several different detectors. Each detector gives different contrast. The most common detectors are: Secondary electron (SE) detector giving a topographical view of the sample, In-lens detector (high magnification SE detector) with less topographical information, and Backscattered electron detector giving an elemental mass contrast (light intensity = heavy element). Energy-dispersive $\mathrm{X}$-ray spectroscopy (EDX) uses the $\mathrm{x}$-rays generated by characteristic electron energy levels transition in each element to extract chemical information of the studied material [94].

In order to image electrically insulating samples without excessive charging and without the need to coat the samples with a thin $(\sim \mathrm{nm})$ conducting metallic film, image settings need to be optimized. A balance needs to be found between lower magnifications/high scan rates which reduce the charging and the sought resolution and quality, which become better with higher magnifications and lower scan rates. Using conducting copper adhesive in a way so that it also covers part of the top of the sample and then performing the analysis in proximity to the $\mathrm{Cu}$ also help to reduce the surface charge.

Chemical analysis with EDX is quick and easy to perform and the quality and capability of the measurements have increased significantly over the last decade with the introduction of new sensor technique and the use of polymer windows instead of Be. The qualitative measurement of the in Paper II used detector is valid down to Be and the quantitative measurement is reliable for heavier elements, above Ne. Significant x-ray fluorescence giving rise to signal in the material next to the right in the period table makes it difficult to quantify $\mathrm{N}$ due to the $\mathrm{C}$-window of the analyzer. This fluorescence may also affect the $\mathrm{O}$-signal to a lesser extent. There is also an overlap between the $\mathrm{O} \mathrm{K}$ peak and the $\mathrm{Cr} \mathrm{L}$ peak that make it difficult to quantify $\mathrm{O}$ when 
having $\mathrm{Cr}$ in the sample. EDX was used for the chemical characterization in Paper II, and due to the mentioned uncertainty for oxygen, only the heavier elements were quantified.

Another chemical analysis technique based on the same electron transitions in the material but analyzed in a different way is electron probe microanalysis (EPMA, Camebax Microbeam) or wavelength-dispersive X-ray spectroscopy (WDX), used for chemical analysis in Paper I. This technique operates in wavelength mode instead of energy mode (EDX) using several different crystals, each one having a distinct wavelength band. The wavelength of the X-rays need to fulfill the brags diffraction condition for each crystal in order to pass to the analyzer. This increase the energy resolution significantly ( $\sim 10$ times better resolution than EDX) but also increase the acquisition time significantly. However system development, with more automation, make this historically slow and difficult to use technique more accessible, even working simultaneously with the EDX as a survey scan and WDX for high resolution measurements. Hence combining the increased energy resolution of WDX with standard samples also permit to quantify the O-content in the coatings with WDX [94].

\subsection{X-ray diffraction (XRD)}

$\mathrm{XRD}$ is a powerful and easy-to-access materials characterization technique permitting to determine the crystal structure of the sample through a nondestructive method without the need of prior sample preparation. The underlying principle is that when the wavelength of the incoming rays, irradiating the sample surface, have the same order of magnitude as the atomic spacing ( $0.15 \AA-0.4 \AA)$ diffraction is possible, similar as to what is observed in optics for visible light diffracted through a grating. There are several possible scattering mechanisms active when exposing the sample with X-rays. The one resulting in diffraction patterns characteristic for the crystal structure is elastic scattering on the electron, called Thomson scattering. In this type of scattering the wavelength of the x-rays is conserved when scattered and obey Bragg's law $2 d_{h k l} \sin \theta=\lambda$. This law states that for an X-ray wavelength $(\lambda)$ constructive interference for lattice planes having a distance $d_{h k l}$ will occur when the incoming $x$-ray angle $(\theta)$ fulfils Bragg's law. The most basic and commonly used X-ray diffraction setup is having a symmetric incoming and outgoing beam using slits for controlling the $\mathrm{x}$-rays divergence (resolution). This setup is called $\theta-2 \theta$ Bragg-Brentano. The symmetric angle used results in that only the planes parallel to the sample surface will fulfill the Bragg condition. For polycrystalline samples without high preferential orientation, this setup is enough to yield a good average of the samples crystal structure. Since this work deals with thin films on a bulk substrate the $\mathrm{x}$-rays will penetrate into the substrate yielding reflections both from the coating and the substrate. These peaks may overlap and cause problems when interpreting the results. A way to mitigate this problem is to use grazing incidence, a non-symmetric diffraction setup, where the incoming angle is fixed at a low angle (typically $\sim 1^{\circ}$ ) and the acquisition angle is varied in order for probing $2 \theta$ angles fulfilling Bragg's law. In grazing incidence configuration, the $x$-ray 
penetration depth is reduced and the x-rays are spread over a larger sample surface. This results in higher coating/substrate signal ratio or even keeping the diffraction only to be within the coating thickness [95].

In Paper I, X-ray diffraction (XRD, Seifert-Meteor, $\mathrm{Cu}_{\mathrm{K} \alpha}$ ) in Bragg-Brentano mode was used in order to determine the crystal structure of the coatings. Some overlap between the coating and substrate was observed, which was interpreted with the help of transmission electron microscopy (TEM) permitting to study the coatings crystal structure in detail without substrate interactions, a characterization technique explained in the next chapter.

\subsection{Transmission electron microscopy (TEM)}

TEM is, like SEM, based on accelerating electrons in order to probe the material properties.

The electrons inside TEM are accelerated to very high energies (200-300 kV acceleration voltage was used in this work) which results in short wavelengths, in the picometer range $\left(10^{-12} \mathrm{~m}\right)$, permitting material analysis with atomic resolution [96].

High energy electrons strongly interacts with materials. In order to perform TEM analysis, the sample thickness should therefore be reduced enough to achieve electron transparency. The TEM sample thickness needed for this to be achieved depends on the elements present in the sample as well as the acceleration voltage used in TEM, but typically it should be below 100 $\mathrm{nm}$. The main drawback with TEM is the time consuming, difficult and destructive (to the original sample) sample preparation, which can even create preparation artifact in the sample if not performed carefully. Due to the small sample volume, care needs to be taken in order to obtain the sought sample area within the thin electron transparent region. If the sample is anisotropic, considerations about sample cut direction is important, as was the case for Paper I. If for example a phase has been observed on the macroscopic scale with a large sample volume technique as XRD it is not easy to discard those findings with TEM since the sample volume analyzed with TEM is so small. Rather TEM is used for finding a more detailed description of what is already observed with the large sampling volume techniques [96].

Once high energy electrons interacts with the electron transparent sample, they will be transmitted through, and scattered by the sample. Depending on the interaction mechanisms involved, various imaging and spectroscopy techniques can be applied in order to characterize the material on atomic level. The transmission electron microscope can be operated in two main modes: Transmission (TEM) or scanning transmission (STEM) mode. In ordinary TEM mode, a parallel electron beam is illuminating the sample, and apertures are controlling from which part of the sample that should give rise to mass/thickness, diffraction or phase contrast image reconstructions. In STEM mode, the electron beam is focused to a probe converged to a sub$\mathrm{nm}$ spot which then is scanned over the sample surface enabling high resolution imaging and local chemical information through detecting emitted X-rays (EDX-spectroscopy) [96]. 
The basic principle for EDX analysis in TEM is the same as for EDX in SEM, described under chapter 3.3. The main difference is that the high energy electrons on a small sample volume make it risky to perform long time mapping scans. The sample may be damaged or phase transformation may even be initiated due to the energy transmitted from the bombarding electrons to the studied area. Therefore, high resolution mapping is only possible with new large area detector EDX positioned close to the sample (like the SuperX EDX system used on FEI $\operatorname{Titan}^{3}$ in Paper I). These new EDX-detectors significantly reduce the acquisition time (from hours to minutes). Less time also means less sample drift while measuring, hence better image quality. A positive aspect of using EDX with TEM, as opposed to in SEM, is the insignificant absorption in the sample of the emitted x-rays due to the small sample volume. This leads to better spatial resolution. On the other hand, the small sample volume results in less signal which may lead to low signal to noise ratio, especially when making quick scans in order to protect the sample from irradiation damage.

With samples consisting of nanocrystalline material it is difficult to obtain atomic resolution since there are often several grains present, stacked on top of each other even though the sample is prepared to optimal TEM-sample thickness ( $<50 \mathrm{~nm}$ thick). If not studying atomically flat 2D materials like graphene, one always studies columns of atoms which need to be orientated parallel with the incoming electron beam in order to image the atomic arrangement. Not having this long range arrangement in nanocrystalline material makes the analysis more difficult and requires extensive searching for grains with the correct orientation. The grains need to be situated in a sample region being sufficiently thin for a high degree of electrons transmission combined with a low degree of grain overlap and the orientation revealing characteristics zone axes of the material. See Paper I for an example of where the adequate grains have been found which made it possible to determine the bcc Cr-phase in the annealed coating.

The TEMs used in the present work were an FEI Tecnai G2 TF20 UT and the Linköping monochromated double-spherical-aberration-corrected FEI Titan ${ }^{3}$. The latter one is state of the art and made the high resolution STEM and EDX micrographs in Paper I possible through the used probe aberration corrector. The aberration correctors compensates aberrations in the electromagnetic "lenses" resulting in better spatial resolution [96]. 


\section{Main results and contribution to the field}

The main goal of this thesis is to synthesize and characterize new pseudo-binary and ternary oxide compounds with mechanical and thermal properties relevant to metal machining. In Paper I, reactive RF-magnetron sputtering was used to grow Cr-rich corundum structure $(\mathrm{Cr}, \mathrm{Zr})_{2} \mathrm{O}_{3}$ thin films at $500{ }^{\circ} \mathrm{C}$. These coatings were subsequently annealed in vacuum up to $870{ }^{\circ} \mathrm{C}$. To investigate the thermal stability of the synthesized oxide compounds is crucial since the temperature during machining becomes high in combination with mechanical loads. The performed characterization of the annealed samples show the transformation of $\alpha-(\mathrm{Cr}, \mathrm{Zr})_{2} \mathrm{O}_{3}$ and amorphous $\mathrm{ZrO}_{\mathrm{x}}$-rich areas into tetragonal $\mathrm{ZrO}_{2}$ and bcc $\mathrm{Cr}$. The presence of the tetragonal $\mathrm{ZrO}_{2}$ phase also at room temperature was linked to its small grain size, stabilizing it compared to the thermodynamically stable monoclinic phase, due to surface energy effects.

The proved stabilization of the tetragonal phase is important since the monoclinic phase cannot be used in high temperature applications requiring mechanical stability. It would transform into the tetragonal phase with accompanied volume contraction. The instability of the present $\alpha-\mathrm{Cr}_{0.28} \mathrm{Zr}_{0.10} \mathrm{O}_{0.61}$ with some amorphous $\mathrm{ZrO}_{\mathrm{x}}$ phase is surprising and possibly related to the annealing being done under vacuum. The observed phase segregation of $\alpha$ $(\mathrm{Cr}, \mathrm{Zr})_{2} \mathrm{O}_{3}$ and formation of tetragonal $\mathrm{ZrO}_{2}$ with hardness increase for a new pseudo-binary oxide system opens up future design routes for pseudo-binary oxides with tunable microstructural and mechanical properties.

Depositing isolating hard oxide coatings with cathodic arc techniques is challenging. The main obstacle is to achieve a stable deposition process when dielectric film forms on all surfaces in the chamber, including the cathode. The work presented in Paper II deals with the specific aim to reduce the uneven cathode erosion, and detrimental oxide island formation on the cathode, when depositing $(\mathrm{Al}, \mathrm{Cr})_{2} \mathrm{O}_{3}$. Previous work claims that adding $\mathrm{Si}$ to the $\mathrm{Al}-\mathrm{Cr}$ cathode reduces the oxide island formation without incorporating $\mathrm{Si}$ in the coating. In Paper II, the plasma composition was studied, when arcing from $\mathrm{Al}_{0.7} \mathrm{Cr}_{0.3}$ and $\mathrm{Al}_{0.7} \mathrm{Cr}_{0.25} \mathrm{Si}_{0.05}$ cathodes in $\mathrm{O}_{2}$ atmosphere. This was done in order to link the plasma composition, to the process parameters: oxygen flow and cathode arc current, as well as the final coating properties.

The study showed small improvements, almost within the error bars, in cathode erosion and process stability (lower pressure and cathode voltage) when introducing 5 at \% Si in the AlCrcathode. Also slightly less droplet formation was observed at low cathode current and intermediate $\mathrm{O}_{2}$-flow when introducing $\mathrm{Si}$. Larger effect with respect to cleaning the cathode from oxide contamination was observed when increasing cathode current with 50\%. However, higher cathode current also resulted in increased droplet formation which is not desired.

Through plasma analysis in Paper II, the presence of volatile $\mathrm{SiO}$ species could be confirmed. These species have previously not been reported in cathodic arc plasma analysis, 
but have been proposed being the origin of Si-loss observed in earlier published work [9]. In Paper II, the presence of Si could be confirmed in all three deposition fluxes (ions, neutrals and macro particles) resulting in similar coating and cathode metal composition. The conclusion is therefore that, the loss of $\mathrm{Si}$ through volatile $\mathrm{SiO}$ species is negligible, in this study. From previous work, both theoretical and experimentally, $\mathrm{Si}$ is known to destabilize the corundum phase and stabilize the $\gamma$-phase for pure $\mathrm{Al}_{2} \mathrm{O}_{3}$, counteracting the addition of $\mathrm{Cr}$, present for promoting the sought corundum phase formation. This results in that the observed small positive effect of $\mathrm{Si}$ at the cathode side may be detrimental at the substrate side. This effect needs to be considered for future industrial optimization. 


\section{Future work}

Regarding the $(\mathrm{Cr}, \mathrm{Zr})_{2} \mathrm{O}_{3}$ study, the results presented here open up for further annealing studies in other atmospheres and pressure (e.g. air at atmospheric pressure) in order to elucidate the stability of the $(\mathrm{Cr}, \mathrm{Zr})_{2} \mathrm{O}_{3}$ pseudo-binary compound. Doing the annealing at a synchrotron and performing in-situ XRD would give data showing the phases existing at temperature relevant for metal machining and also provide the detailed transformation route. The coating system may also be further stabilized by changing the deposition method and applying bias. This could be the subject of a next annealing study.

As part of the study for investigating the Al-Cr-(Si)-O system, similar depositions have been performed, scanning the effect of $\mathrm{O}_{2}$ flow and $\mathrm{Si}$ content for two $\sim \mathrm{Al} / \mathrm{Cr}$-ratios, in the same type of deposition system (Oerlikon Balzers, Innova) as was used in the study [9] claiming better cathode erosion when adding $\mathrm{Si}$ in the cathode without incorporating $\mathrm{Si}$ in the coating. Linking property analysis such as SEM, XRD, TEM, x-ray photoelectron spectroscopy (XPS) and nano indentation of those coatings with the present plasma study will give a better and more complete understanding of the plasma as well as the final coating properties in this pseudo-ternary oxide system. It would also be beneficial to perform metal cutting tests of these new coatings, in order to correlate the mechanical, chemical and microstructural evolution to actual coating wear resistance.

In addition to the above mentioned topics, my future work will be devoted to reactive pulsed DC magnetron sputtering with pulsed bias in a lab scale UHV system, surveying Al-based pseudo-binary oxide alloys. The goal is to obtain new thermodynamically stable phases such as pseudo-binary corundum structured materials, or kinetically stabilized cubic spinel-like structures ( $\gamma$-like phases) that would show suitable material properties for metal cutting applications. Upon finding new material system with relevant properties in the lab scale deposition equipment applicability to industrial scale will be considered. The use of HIPIMS to this work would be an interesting addition since having ionized metal species in sputtering has been showed to be beneficial for achieving thermodynamically stable materials at low deposition temperatures. 


\section{Bibliography}

1. Aronsson, B., The origins and growth of cemented carbide : with emphasis on the development within the Sandvik Group companies. 2005: Ord\&Form AB.

2. Ruppi, S. Advances in chemically vapour deposited wear resistant coatings. in Journal De Physique. IV : JP. 2001.

3. Jack, D.H., Ceramic cutting tool materials. Materials \& Design, 1986. 7(5): p. 267-273.

4. Ruppi, S., Enhanced performance of $\alpha$-Al2O3 coatings by control of crystal orientation. Surface and Coatings Technology, 2008. 202(17): p. 4257-4269.

5. Quinto, D.T., Mechanical property and structure relationships in hard coatings for cutting tools. Journal of Vacuum Science \& Technology A, 1988. 6(3): p. 2149-2157.

6. Münz, W.D., Titanium aluminum nitride films: A new alternative to TiN coatings. Journal of Vacuum Science \& Technology A, 1986. 4(6): p. 2717-2725.

7. Mayrhofer, P.H., et al., Self-organized nanostructures in the Ti-Al-N system. Applied Physics Letters, 2003. 83(10): p. 2049-2051.

8. Leyendecker, T., et al., The development of the PVD coating TiAIN as a commercial coating for cutting tools. Surface and Coatings Technology, 1991. 48(2): p. 175-178.

9. Paulitsch, J., et al., Influence of Si on the target oxide poisoning during reactive arc evaporation of $(\mathrm{Al}, \mathrm{Cr}) 2 \mathrm{O} 3$ coatings. Vacuum, 2014. 100: p. 29-32.

10. M'Saoubi, R. and S. Ruppi, Wear and thermal behaviour of CVD $\alpha-A / 2 O 3$ and MTCVD Ti(C,N) coatings during machining. CIRP Annals - Manufacturing Technology, 2009. 58(1): p. 57-60.

11. Bouzakis, K.D., et al., Cutting with coated tools: Coating technologies, characterization methods and performance optimization. CIRP Annals - Manufacturing Technology, 2012. 61(2): p. 703-723.

12. Bejjani, R., et al., Multi-scale study of initial tool wear on textured alumina coating, and the effect of inclusions in low-alloyed steel. Tribology International, 2016. 100: p. 204-212.

13. Gerth, J., et al., Adhesion phenomena in the secondary shear zone in turning of austenitic stainless steel and carbon steel. Journal of Materials Processing Technology, 2014. 214(8): p. 1467-1481.

14. Kondo, S., K. Tateishi, and N. Ishizawa, Structural evolution of corundum at high temperatures. Japanese Journal of Applied Physics, 2008. 47(1 PART 2): p. 616-619.

15. Kronberg, M.L., Plastic deformation of single crystals of sapphire: Basal slip and twinning. Acta Metallurgica, 1957. 5(9): p. 507-524.

16. Zywitzki, O., et al., Effect of the substrate temperature on the structure and properties of Al2O3 layers reactively deposited by pulsed magnetron sputtering. Surface and Coatings Technology, 1996. 82(1): p. 169-175.

17. Fietzke, F., K. Goedicke, and W. Hempel, The deposition of hard crystalline Al2O3 layers by means of bipolar pulsed magnetron sputtering. Surface and Coatings Technology, 1996. 86: $\mathrm{p}$. 657-663.

18. Zywitzki, O. and G. Hoetzsch, Correlation between structure and properties of reactively deposited Al2O3 coatings by pulsed magnetron sputtering. Surface and Coatings Technology, 1997. 94: p. 303-308.

19. Sarakinos, K., et al., lonized physical vapor deposited Al2O3 films: Does subplantation favor formation of alpha-Al2O3? Physica Status Solidi-Rapid Research Letters, 2010. 4(7): p. 154156.

20. Music, D., et al., Ab initio molecular dynamics of Al irradiation-induced processes during Al2O3 growth. Applied Physics Letters, 2011. 98(11).

21. Yamada-Takamura, Y., et al., Characterization of $\alpha$-phase aluminum oxide films deposited by filtered vacuum arc. Surface and Coatings Technology, 2001. 142-144: p. 260-264. 
22. Wallin, E., et al., Synthesis of $\alpha$-Al2O3 thin films using reactive high-power impulse magnetron sputtering. EPL, 2008. 82(3): p. 36002.

23. Selinder, T.I., et al., $\alpha$-Alumina coatings on WC/Co substrates by physical vapor deposition. International Journal of Refractory Metals and Hard Materials, 2009. 27(2): p. 507-512.

24. Andersson, J.M., et al., Phase control of Al2O3 thin films grown at low temperatures. Thin Solid Films, 2006. 513(1-2): p. 57-59.

25. Levin, I. and D. Brandon, Metastable Alumina Polymorphs: Crystal Structures and Transition Sequences. Journal of the American Ceramic Society, 1998. 81(8): p. 1995-2012.

26. Levin, I. and D.G. Brandon, A new metastable alumina polymorph with monoclinic symmetry. Philosophical Magazine Letters, 1998. 77(2): p. 117-124.

27. Zhou, R.S. and R.L. Snyder, Structures and transformation mechanisms of the $\eta, v$ and $\vartheta$ transition aluminas. Acta Crystallographica Section B, 1991. 47(5): p. 617-630.

28. Ruppi, S., A. Larsson, and A. Flink, Nanoindentation hardness, texture and microstructure of $\alpha$ Al2O3 and $k-A / 2 O 3$ coatings. Thin Solid Films, 2008. 516(18): p. 5959-5966.

29. Zeman, P., et al., Thermally activated transformations in metastable alumina coatings prepared by magnetron sputtering. Surface and Coatings Technology, 2014. 240(0): p. 7-13.

30. Schütze, A. and D.T. Quinto, Pulsed plasma-assisted PVD sputter-deposited alumina thin films. Surface and Coatings Technology, 2003. 162(2-3): p. 174-182.

31. Musil, J., et al., Thermal stability of alumina thin films containing $\gamma$-Al2O3 phase prepared by reactive magnetron sputtering. Applied Surface Science, 2010. 257(3): p. 1058-1062.

32. Trinh, D.H., et al., Nanocomposite Al2O3-ZrO2 thin films grown by reactive dual radiofrequency magnetron sputtering. Thin Solid Films, 2008. 516(15): p. 4977-4982.

33. Witthaut, M., et al., Preparation of Cr2O3-A/2O3 solid solutions by reactive magnetron sputtering. Mikrochimica Acta, 2000. 133(1-4): p. 191-196.

34. Sridharan, M., et al., Pulsed DC magnetron sputtered Al2O3 films and their hardness. Surface and Coatings Technology, 2007. 202(4-7): p. 920-924.

35. Nahif, F., et al., Ab initio study of the effect of Si on the phase stability and electronic structure of gamma- and alpha-Al2O3. J Phys Condens Matter, 2013. 25(12): p. 125502.

36. Nahif, F., et al., The effect of Si alloying on the thermal stability of Al2O3 films deposited by filtered cathodic arc. Surface \& Coatings Technology, 2013. 235: p. 250-258.

37. Muller, M.G.J., et al., Transmission electron microscopy investigation of the effect of Si alloying on the thermal stability of amorphous alumina thin films deposited by filtered cathodic arc deposition. Surface \& Coatings Technology, 2014. 257(0): p. 338-347.

38. Bolvardi, H., et al., Effect of Si additions on thermal stability and the phase transition sequence of sputtered amorphous alumina thin films. Journal of Applied Physics, 2015. 117(2): p. -.

39. Klocke, F., et al., Analyses of the Performance Potential of Oxidic PVD Wear-Protection Coatings on Cutting Tools Using the Example of Crystalline $\gamma$-Al2O3. Advanced Engineering Materials, 2008. 10(7): p. 622-627.

40. Cordes, S.E., Thermal stability of $\gamma$-alumina PVD coatings and analysis of their performance in machining of austenitic stainless steels. CIRP Journal of Manufacturing Science and Technology, 2012. 5(1): p. 20-25.

41. Astrand, M., et al., PVD-Al2O3-coated cemented carbide cutting tools. Surface \& Coatings Technology, 2004. 188: p. 186-192.

42. Castaldi, L., et al., Effect of the oxygen content on the structure, morphology and oxidation resistance of $\mathrm{Cr}-\mathrm{O}-\mathrm{N}$ coatings. Surface and Coatings Technology, 2008. 203(5-7): p. 545-549.

43. Barshilia, H.C. and K.S. Rajam, Growth and characterization of chromium oxide coatings prepared by pulsed-direct current reactive unbalanced magnetron sputtering. Applied Surface Science, 2008. 255(5, Part 2): p. 2925-2931.

44. Hones, P., M. Diserens, and F. Levy, Characterization of sputter-deposited chromium oxide thin films. Surface \& Coatings Technology, 1999. 120: p. 277-283. 
45. Pedersen, K., et al., Texture and microstructure of $\mathrm{Cr} 2 \mathrm{O} 3$ and $(\mathrm{Cr}, \mathrm{Al}) 2 \mathrm{O} 3$ thin films deposited by reactive inductively coupled plasma magnetron sputtering. Thin Solid Films, 2010. 518(15): p. 4294-4298.

46. Jin, P., et al., Low temperature deposition of alpha-Al2O3 thin films by sputtering using a Cr2O3 template. Journal of Vacuum Science \& Technology a-Vacuum Surfaces and Films, 2002. 20(6): p. 2134-2136.

47. Andersson, J.M., et al., Microstructure of $\alpha$-alumina thin films deposited at low temperatures on chromia template layers. Journal of Vacuum Science \& Technology A, 2004. 22(1): p. 117121.

48. Eklund, P., et al., $\alpha$-Cr2O3 template-texture effect on $\alpha$-Al2O3 thin-film growth. Thin Solid Films, 2008. 516(21): p. 7447-7450.

49. Spitz, S., et al., Microstructure evolution of radio-frequency magnetron sputtered oxide thin films in the Cr-Zr-O system. Thin Solid Films, 2013. 548: p. 143-149.

50. Ramm, J., et al., Pulse enhanced electron emission (P3 $\left.e^{T M}\right)$ arc evaporation and the synthesis of wear resistant $\mathrm{Al}-\mathrm{Cr}-\mathrm{O}$ coatings in corundum structure. Surface and Coatings Technology, 2007. 202(4-7): p. 876-883.

51. Diechle, D., et al., Combinatorial approach to the growth of $\alpha-(\mathrm{Al} 1-x, \mathrm{Cr} x) 2+\delta(\mathrm{O} 1-\mathrm{y}, \mathrm{Ny}) 3$ solid solution strengthened thin films by reactive r.f. magnetron sputtering. Surface and Coatings Technology, 2011. 206(7): p. 1545-1551.

52. Hones, P., F. Levy, and N.X. Randall, Influence of deposition parameters on mechanical properties of sputter-deposited Cr2O3 thin films. Journal of Materials Research, 1999. 14(9): p. 3623-3629.

53. Graham, H.C. and H.H. Davis, Oxidation/Vaporization Kinetics of Cr2O3. Journal of the American Ceramic Society, 1971. 54(2): p. 89-93.

54. Howard, C.J., R.J. Hill, and B.E. Reichert, Structures of the Zro2 Polymorphs at RoomTemperature by High-Resolution Neutron Powder Diffraction. Acta Crystallographica Section B-Structural Science Crystal Engineering and Materials, 1988. 44: p. 116-120.

55. Simeone, D., et al., Monoclinic to tetragonal semireconstructive phase transition of zirconia. Physical Review B, 2003. 67(6): p. 064111.

56. Fabrichnaya, O., et al., Phase equilibria and thermodynamic properties of the ZrO2-GdO1.5Y01.5 system. Journal of Phase Equilibria and Diffusion, 2005. 26(6): p. 591-604.

57. Krogstad, J.A., et al., Effect of Yttria Content on the Zirconia Unit Cell Parameters. Journal of the American Ceramic Society, 2011. 94(12): p. 4548-4555.

58. Swab, J., Role of Oxide Additives in Stabilizing Zirconia for Coating Applications. Army Research Laboratory, 2001.

59. Nettleship, I. and R. Stevens, Tetragonal zirconia polycrystal (TZP)-A review. International Journal of High Technology Ceramics, 1987. 3(1): p. 1-32.

60. Park, S.D., J.M. Vohs, and R.J. Gorte, Direct oxidation of hydrocarbons in a solid-oxide fuel cell. Nature, 2000. 404(6775): p. 265-267.

61. Sonderby, S., et al., Industrial-scale high power impulse magnetron sputtering of yttriastabilized zirconia on porous NiO/YSZ fuel cell anodes. Surface \& Coatings Technology, 2015. 281: p. 150-156.

62. Giaquinta, D.M. and H.-C. zur Loye, Structural Predictions in the ABO3 Phase Diagram. Chemistry of Materials, 1994. 6(4): p. 365-372.

63. Martin, R.M., Electronic structure, basic theory and practical methods. 2004.

64. Abrikosov, I.A., et al., Phase Stability and Elasticity of TiAIN. Materials, 2011. 4(9): p. 15991618.

65. Music, D., R.W. Geyer, and J.M. Schneider, Recent progress and new directions in density functional theory based design of hard coatings. Surface and Coatings Technology, 2016. 286: p. 178-190. 
66. Khatibi, A., et al., Structural and mechanical properties of corundum and cubic (AlxCr1-x)2+yO3-y coatings grown by reactive cathodic arc evaporation in as-deposited and annealed states. Acta Materialia, 2013. 61(13): p. 4811-4822.

67. Feuerstein, A., et al., Technical and Economical Aspects of Current Thermal Barrier Coating Systems for Gas Turbine Engines by Thermal Spray and EBPVD: A Review. Journal of Thermal Spray Technology, 2008. 17(2): p. 199-213.

68. Shannon, R., Revised effective ionic radii and systematic studies of interatomic distances in halides and chalcogenides. Acta Crystallographica Section A, 1976. 32(5): p. 751-767.

69. Jerebtsov, D.A., G.G. Mikhailov, and S.V. Sverdina, Phase diagram of the system: ZrO2-Cr2O3. Ceramics International, 2001. 27(3): p. 247-250.

70. Garvie, R.C., The Occurrence of Metastable Tetragonal Zirconia as a Crystallite Size Effect. The Journal of Physical Chemistry, 1965. 69(4): p. 1238-1243.

71. Baldinozzi, G., et al., Neutron Diffraction Study of the Size-Induced Tetragonal to Monoclinic Phase Transition in Zirconia Nanocrystals. Physical Review Letters, 2003. 90(21): p. 216103.

72. Kim, S.S. and T.H. Jr. Sanders, Thermodynamic Modeling of the Isomorphous Phase Diagrams in the Al2O3-Cr2O3 and V2O3-Cr2O3 Systems. Journal of the American Ceramic Society, 2001. 84(8): p. 1881-1884.

73. Besmann, T.M., N.S. Kulkarni, and K.E. Spear, Thermochemical Analysis and Modeling of the Al2O3-Cr2O3, Cr2O3-SiO2, and Al2O3-Cr2O3-SiO2 Systems Relevant to Refractories. Journal of the American Ceramic Society, 2006. 89(2): p. 638-644.

74. Khatibi, A., et al., Face-centered cubic (Al1-xCrx)2O3. Thin Solid Films, 2011. 519(8): p. 24262429.

75. Kurapov, D., Non gamma - phase cubic AlCrO. 2010.

76. Alling, B., et al., Theoretical investigation of cubic B1-like and corundum ( $\mathrm{Cr} 1-x \mathrm{Al} x) 2 \mathrm{O} 3$ solid solutions. Journal of Vacuum Science \& Technology A: Vacuum, Surfaces, and Films, 2013. 31(3): p. 030602.

77. Najafi, H., et al., Formation of cubic structured (Al1-xCrx)2+8O3 and its dynamic transition to corundum phase during cathodic arc evaporation. Surface and Coatings Technology, 2013. 214(0): p. 46-52.

78. Ramm, J., et al., Correlation between target surface and layer nucleation in the synthesis of Al$\mathrm{Cr}-\mathrm{O}$ coatings deposited by reactive cathodic arc evaporation. Surface \& Coatings Technology, 2010. 205(5): p. 1356-1361.

79. Pohler, M., et al., Cathodic arc deposition of (Al,Cr)2O3: Macroparticles and cathode surface modifications. Surface and Coatings Technology, 2011. 206(6): p. 1454-1460.

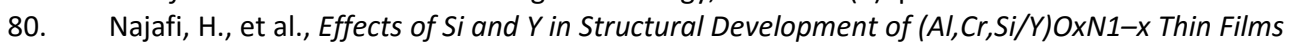
Deposited by Magnetron Sputtering. Thin Solid Films, 2013(0).

81. Greene, J.E., Tracing the 5000-year recorded history of inorganic thin films from $\sim 3000$ BC to the early 1900s AD. Applied Physics Reviews, 2014. 1(4): p. 041302.

82. Martin, P.M., Handbook of deposition technologies for films and coatings. [electronic resourse] : science, applications and technology, third edition. 2010: Oxford, U.K. ; Burlington, Mass. : William Andrew/Elsevier, c2010 3rd ed.

83. Jousten, K., Handbook of vacuum technology. 2008: Weinheim : Wiley-VCH, cop. 2008.

84. Jackson, G.N., R.F. sputtering. Thin Solid Films, 1970. 5(4): p. 209-246.

85. Helmersson, U., et al., lonized physical vapor deposition (IPVD): A review of technology and applications. Thin Solid Films, 2006. 513(1-2): p. 1-24.

86. Anders, A., A review comparing cathodic arcs and high power impulse magnetron sputtering (HiPIMS). Surface and Coatings Technology, 2014. 257: p. 308-325.

87. Anders, A., Cathodic Arcs [Elektronisk resurs] : From Fractal Spots to Energetic Condensation. 2009, New York, NY: Springer US.

88. Roth, J.R., Industrial plasma engineering, Vol. 1. Principles. 1995: Bristol : Institute of Physics, 1995-. 
89. Tay, B.K., Z.W. Zhao, and D.H.C. Chua, Review of metal oxide films deposited by filtered cathodic vacuum arc technique. Materials Science and Engineering: R: Reports, 2006. 52(1-3): p. 1-48.

90. Zhirkov, I., et al., Effect of Ti-Al cathode composition on plasma generation and plasma transport in direct current vacuum arc. Journal of Applied Physics, 2014. 115(12).

91. Rosén, J., J.M. Schneider, and A. Anders, Charge state dependence of cathodic vacuum arc ion energy and velocity distributions. Applied Physics Letters, 2006. 89(14): p. 141502.

92. Anders, A. and E. Oks, Charge-state-resolved ion energy distribution functions of cathodic vacuum arcs: A study involving the plasma potential and biased plasmas. Journal of Applied Physics, 2007. 101(4): p. 043304.

93. Zhirkov, I., A.O. Eriksson, and J. Rosen, Ion velocities in direct current arc plasma generated from compound cathodes. Journal of Applied Physics, 2013. 114(21): p. 213302.

94. Goldstein, J.I., Scanning electron microscopy and $x$-ray microanalysis. 2003: New York : Kluwer Academic / Plenum, cop. 2003 3. ed.

95. Birkholz, M., Thin film analysis by $x$-ray scattering. 2006: Weinheim : Wiley-VCH, 2006.

96. Williams, D.B. and C.B. Carter, Transmission electron microscopy : a textbook for materials science. 2009: New York ; London : Springer, cop. 2009 2. ed. 


\section{Papers}

The articles associated with this thesis have been removed for copyright reasons. For more details about these see:

http://urn.kb.se/resolve? urn:nbn:se:liu:diva-134146 